\title{
Did Rural Resentment of Government Employees Elect Donald Trump?
}

\author{
Stephanie M. Carpenter ${ }^{1,2}$ \\ Markus Brauer ${ }^{1}$ \\ Paula M. Niedenthal ${ }^{1}$
}

${ }^{1}$ Department of Psychology, University of Wisconsin-Madison, Madison, WI, USA.

${ }^{2}$ Institute for Social Research, University of Michigan, Ann Arbor, MI, USA.

\section{**This paper is accepted at the Journal of Elections, Public Opinion and Parties**}

Correspondence should be addressed to: Stephanie M. Carpenter, Institute for Social Research, University of Michigan, 426 Thompson St., Ann Arbor, MI, USA, 48106. Phone: (541) 5790546, E-mail: smcarpen@umich.edu

Biographical Notes:

Stephanie M. Carpenter, Ph.D., is a Research Fellow at the University of Michigan Institute for Social Research Survey Research Center. She was formerly a Postdoctoral Trainee at the University of Wisconsin-Madison. Her research examines the role of emotion and cognition in decision behavior. Markus Brauer, Ph.D., is a Professor of Social and Personality Psychology at the University of Wisconsin-Madison. His research is focused on group and inter-group processes, especially as they relate to social power, intergroup perception, and civil courage.

Paula M. Niedenthal, Ph.D., is the Howard Leventhal WARF Professor of Social and Personality at the University of Wisconsin-Madison. Her research is best described as crossing the areas of the Social Psychology of Emotion and the Affective Neurosciences, with a focus on the function of and the processing of emotion. 


\section{Did Rural Resentment of Government Employees Elect Donald Trump?}

A recent "rural resentment" hypothesis holds that the rise of conservative politicians in the state of Wisconsin is explained by rural residents' resentment of beneficiaries of economic advantages, especially government employees (Cramer 2016a). We tested a national rural resentment hypothesis using survey methodology. 3820 respondents representing all 50 US states reported the extent to which they felt resentment- and admiration-related emotions toward public school teachers, state university professors, and agents of departments of natural resources, and reported the presidential candidate they voted for in the 2016 general election. Rural and urban Americans' resentment of government employees was significantly lower than their admiration for members of those groups. Political party affiliation and education predicted resentment of government employees more than did rural-urban residence. Although Americans residing in rural areas were more likely to have voted for Donald Trump than Americans residing in urban areas, resentment of government employees accounted for a relatively small proportion of this effect.

Keywords: emotion, resentment, admiration, public opinion, voting 


\section{Introduction}

Rural versus urban voting behavior has been a topic of intense analysis for decades, with voting patterns being attributed to differing economic and social pressures (Berelson, Lazarsfeld, and McPhee 1954; Gimpel and Schuknecht 2009). A recent account focuses instead on social and political psychological mechanisms of social identity and intergroup emotions. This "rural resentment" account holds that the voting behavior of rural America is driven in large part by feelings of discontent that arise from the perception that urban Americans enjoy unfair and undeserved access to economic resources, including tax revenue and job security (e.g., Cramer 2016a; Kinder and Sanders 1996; McCarty, Poole, and Rosenthal 2006; Nicholson 2012).

Specifically, in a study of political attitudes, Cramer (2016b) conducted interviews with groups of people gathered in public spaces in the state of Wisconsin. The conversations revealed a distressed focus by rural and working-class citizens on government employees (i.e., civil servants) - including and especially public schoolteachers, professors of state universities, and agents of departments of natural resource management - as representatives of an urban agenda. Feelings of resentment toward the perceived outgroups appeared to be fueled by campaign rhetoric that highlighted economic disparities between government employees and "regular" taxpayers, and interpreted the attainment of a so-called job for life as an unfair and undeserved advantage (Cramer 2016a, 2016b).

Resentment of government employees may account for voting beyond the state of Wisconsin. Numerous observations of a rural-urban polarization across the United States suggest a national "us" versus "them" divide (e.g., McCarty, Poole, and Rosenthal 2006; Cramer 2016b; Brownstein 2008; Druckman, Peterson, and Slothuus 2013; Fiorina and Lvendusky 2006). And a related intergroup dynamic between individuals who live in the interior of the United States and 
those who reside in so-called "elite" coastal states has been noted more recently. Political blog posts boasting titles such as "America is held hostage by flyover states" (Townsend 2016) and "The coasts and the 'flyover country' - the great US divide" (Vance 2016a) seem to reveal group identifications that may also be associated with conflicting attitudes about political policies that regulate the allocation of resources. That is, there exist some claims of an interior state resentment of government employees and corresponding shifts to more conservative policies that parallels the rural resentment hypothesis.

The mechanisms of social identity (e.g., "rural consciousness") and intergroup emotion on which the rural resentment hypothesis relies are documented by vast social psychological literatures devoted to the study of intergroup relations (Hogg 2013; Stangor 2004). Individual's identities are derived both from their personal characteristics and histories, as well as their membership in groups (Tajfel and Turner 1986). As with their personal identities, individuals strive to achieve and maintain positive social (i.e. "ingroup") identities, which serve to foster and maintain self-esteem (Ellemers, Kortekaas, and Ouwerkerk 1999). Positive social identities can be bolstered by favorable comparisons between the ingroup and relevant outgroups. During periods of intergroup comparison (as can be caused intentionally by political rhetoric) or conflict, social identities become especially self-defining, and drive people's perceptions of current social and economic conditions (Brown 2000).

Previous studies of voting behavior, as well as exit polls, document the role of ruralurban identity, as well as social identities associated with political party, educational attainment, and gender in public opinion (Jackson 1975; Page and Jones 1979; Inglehart and Norris 2000; Milligan, Oretti, and Oreopulous 2004). These social identities also drive emotional life (Kawakami and Dion 1993): When individuals focus on their social identities, they experience 
emotions on behalf of these groups, including emotions directed toward outgroups (Smith, Spears, and Hamstra 1999). The intergroup emotion of resentment, as well as closely related feelings of anger and disgust, arise from perceptions of unfairness and injustice (cf. Smith 1993), and violations of human dignity and autonomy (Mackie, Smith, and Ray 2008), respectively. In theory, resentment, anger and disgust are similar in being "other-condemning" (Ekman 1993), and plausibly motivate endorsement of political policies aimed at redressing injustices perceived as existing between societal groups. Other-condemning emotions can be contrasted with otherpraising emotions (Rozin, Haidt, and McCauley 1999; Mackie and Smith 2018; Haidt 2003) such as admiration, gratitude and pride. These latter emotions enhance the sense of similarity between the self and others and are associated with more benevolent motivations when felt toward an outgroup (Algoe and Haidt 2009; Oveis, Horberg, and Keltner 2010; Mackie and Smith 2015).

We tested a national rural resentment hypothesis that focused on one specific component of the phenomenon, that is resentment toward state-level civil servants. On this account, individuals living in rural, compared to urban, areas experience resentment toward government employees whom they believe are unfairly advantaged, and these feelings predict support for conservative policies, defined here as voting for Donald Trump in the 2016 US general election. We tested a similar intergroup resentment hypothesis for residents of states interior to the United States versus its "elite" coastal states. We obtained data from a national survey that included measures of respondents' demographic characteristics, resentment- and admiration-related feelings toward government employees - including public school teachers, professors of their state's flagship public universities, and agents of their state's office of natural resource management - and voting in the 2016 US general election. We also added a measure of admiration to test if resentment toward government employees is greater than admiration. 
Although admiration is not mentioned in prior research on rural resentment (Cramer 2016a, 2016b), it provides an opportunity to compare feelings of resentment to another intergroup emotion.

The goal of this study was to provide a quantitative analysis of resentment across the groups of theoretical interest, as well as test the hypothesis that resentment significantly accounts for voting behavior. We first compared levels of resentment versus admiration toward government employees among people of rural versus urban residence and of residence in interior versus coastal US states. We then examined the statistical relationship between geographical residence compared to membership in other social groups (e.g., political party, educational attainment) in determining resentment toward government employees. Next, we estimated the relative importance of resentment as a predictor of voting. And finally, we analyzed the mediating role of resentment in the interaction of rural-urban residence, educational attainment, and gender in voting. This last model tested the specific hypothesis that resentment-motivated voting is particularly evidenced by people who identify as male, are less educated, and are residents of rural areas.

\section{Materials and Methods}

\section{Participants}

A probability sample $(N=3820)$ was recruited through the University of Southern California (USC) Dornsife Center for Economic and Social Research as a part of the large-scale Understanding America Study (UAS). ${ }^{1}$ The UAS is a panel that includes approximately 6,000

\footnotetext{
${ }^{1}$ Another sample of respondents $(N=2280)$ was recruited prior to the UAS sample through advertisements on Amazon Mechanical Turk (MTurk) and Facebook to complete a "US Feeling Survey." This survey yielded similar results to those reported in our main UAS sample (see Supplementary Text S1, Supplementary Text S2, Supplementary Text S3, Tables S1, S3, S7-S9, Figures S4-S5, for details).
} 
households representing the 50 United States. It is conducted as an internet panel, for which respondents answer surveys on a computer, tablet, or smart phone on their own time and wherever is convenient. The Center for Economic and Social Research programs the survey questions sent by researchers from around the world, translates them into Spanish for a subset of the respondents to ensure representativeness of the US population, and then collects the data. UAS recruitment was conducted through address-based sampling (ABS) in which samples were acquired based on zip code draws. Participants received an advance notification letter, followed by several phone and mail-based follow-ups to encourage survey participation. All demographic questions acquired for this sample were already included in the UAS. Data were collected from July to October 2017, and the sample size was determined by the number of participants currently residing in the United States who responded to the survey within this three month time period. No participants in this sample were excluded from analyses. A study approval status of "exempt" was granted by the University of Wisconsin-Madison Institutional Review Board.

\section{Survey and Procedure}

The UAS includes items that assess demographic variables of interest to the present analysis and also respondents' vote in the 2016 general election. To one wave of the survey, we contributed 21 questions that measured respondents' feelings toward government employees of their current state of residence. The groups of government employees evaluated were public school teachers, university professors at the state's flagship (i.e., major public) institution(s), and agents of their state's natural resource agency (e.g., Department of Natural Resources). The three categories of government employees were selected based on prior research suggesting that these groups are especially likely to evoke negative feelings, including resentment, from people living in rural parts of the state (Cramer 2016a). 
Respondents rated, on scales ranging from 0 (not at all) to 3 (very much), the degree to which the members of these three categories of government employees made them feel each of nine different feeling states (i.e., resentment emotions: anger, resentment, disgust; admiration emotions: pride, admiration, gratefulness; negative filler emotions: fear, shame, jealousy). The adjective for "disgust" was translated as "indignation" for the Spanish speaking sample, because the exact translation "disgust" is not used when evaluating people (as opposed to objects) in the Spanish language.

As described above, from a theoretical standpoint and based on the intercorrelations (Table S2), resentment, anger, and disgust are the most closely related negative emotions. Resentment has been linked to anger, and particularly anger elicited by a target that is perceived as having committed some wrong (Ekman 1993). Furthermore, both anger and moral disgust are thought of as moral emotions that share an other-condemning quality (Algoe and Haidt 2009, Oveis, Horberg, and Keltner 2010, Haidt 2003). Thus, we included anger, resentment, and disgust as our other-condemning resentment emotions. Similarly, we included pride, admiration, and gratefulness as our other-praising emotions (Algoe and Haidt 2009, Oveis, Horberg, and Keltner 2010) and found that these feelings toward government workers were highly correlated in our sample (Table S2). Respondents then reported their vote in the 2016 election and completed demographic questions. A complete list of demographics, including frequencies by state, gender, political party affiliation, education, age, and race/ethnicity are reported in supporting information (Table S1).

\section{Feelings About Government Employees}

For each of the nine emotion adjectives, we averaged the ratings across the three government employee categories. To ensure that collapsing across the three was appropriate, we 
conducted reliability analyses. Cronbach's alphas were high for all nine emotion adjectives compared across the three groups, ranging from $\alpha=.519$ to $.724(M=.60, S D=.05)$.

Respondents reported a moderate degree of pride $(M=1.76, S D=.67)$, admiration $(M=1.78$, $S D=.67)$, and gratefulness $(M=1.79, S D=.67)$, and a slight degree of resentment $(M=.68, S D$ $=.49)$, anger $(M=.71, S D=.51)$, and disgust/indignation $(M=.94, S D=.65)$, as well as other negative emotions: fear $(M=.61, S D=.44)$, shame $(M=.65, S D=.47)$, and jealousy $(M=.55$, $S D=.37)$ toward the government employees.

\section{Coding of Variables}

Rural, mixed, urban. In the UAS, respondent's rural-urban residence status is determined by the definition used by the US Census Bureau, which is based on population density and other measures of dense development. These determinations are linked to respondents by zip code, specifically using data describing the 2010 Urban Area to ZIP Code Tabulation Area (ZCTA) relationship. In other words, the 3-level rural-urban residence measure calculated by the UAS was based on the ZCTA relationship, and not any other classification. The rural-urban residence variable was coded as urban (0), mixed urban/rural (1), or rural (2).

Interior versus "elite" coastal states. We also compared the attitudes and voting behavior of residents of interior states to those residing in the "elite" coastal states of the United States as a separate intergroup analysis. Since there is no formal definition of this distinction, "elite" coastal states were identified primarily based on mainstream media and political website definitions (cf. Townsend 2016; Vance 2016a, 2016b). These included: New York, Connecticut, Vermont, Massachusetts, Rhode Island, Maryland, New Jersey, Delaware, California, Washington, Oregon, and Washington D.C. For simplicity, states outside of this group were referred to as the interior states. It should be noted that the present distinction corresponds to an 
"us" versus "them" intergroup perception that is based in social identities, not purely geographical realities (e.g., note that a subset of coastal states, such as those of the South and New Hampshire, are not typically grouped in with "elite" coastal states due to political and social trends that make them distinct; cf. Barrick, Lavoie, and Haverty 2016; Harkins 2016). Social distinctions between the "elite" coastal states and the interior of the United States go beyond public perceptions that meaningful political party leanings exist at the state-level (cf. Baldassarri and Gelman, 2008; Barrick, Lavoie, and Haverty 2016; Harkins 2016; Townsend 2016; Vance 2016a, 2016b); however, these distinctions still roughly correspond to "us" versus "them" groupings created by political candidates, commentators, and analysts across the political spectrum. There is also a relationship between the rural-urban divide and the interior versus coastal state divide insofar as the "elite" coastal states contain or are adjacent to ethnically and racially diverse urban centers. However, because diverse urban centers such as Houston, Atlanta, Denver, and Chicago also exist in interior states, the present analysis is not considered to be a replication of the analyses using the rural-urban classification, but instead another way to examine residence-based "us" versus "them" perceptions that could be linked to voting motivated by resentment of government employees. Accordingly, we generated a binary variable reflecting residence in an "elite" coastal (0) or interior (1) state.

Educational attainment, party affiliation, and gender. The correlations among educational attainment, party affiliation, and gender are reported in Table S3. The coding for demographic variables can be found in the captions of Figure 3 and Figure 4. For analyses containing interaction terms, all predictor variables were mean centered. 
Voting in the 2016 general election. For all analyses, we used as the dependent measure a binary vote variable to represent voting for Clinton (0) or Trump (1). Participants who did not vote or who voted for other candidates were excluded from analyses (see Table S1).

\section{Results}

Relationship between resentment and admiration. We first computed two theoretically driven indexes of the two intergroup emotions (Table S2). Resentment scores were the average of reported resentment, anger and disgust (Cronbach's $\alpha=.754$ ), and admiration scores were the average of reported admiration, gratitude and pride (Cronbach's $\alpha=.875$ ) toward the three government employee groups. We then computed bivariate correlations between the two feeling indices. The correlation was negative but small, $r=-.105, p<.001$, indicating that the two intergroup emotions are not simply opposites and it is sensible to compare the levels of both feelings.

Resentment, admiration, and the rural-urban divide. A 3 (rural, mixed, urban) x 2 (resentment, admiration) mixed-model ANOVA (see Judd, McClelland, and Ryan 2017) with repeated measures on the second factor revealed that Americans were significantly more admiring $(M=1.77, S D=.60)$ than resentful $(M=.78, S D=.46)$ of government employees, $F(1$, $3394)=5046.91, p<.001 .^{2}$ The interaction between feelings of resentment and admiration and rural-urban residence was also significant $(F(2,3394)=8.40, p<.001)$. The interaction was

\footnotetext{
${ }^{2}$ Note that analyses presented here were conducted with unweighted data. Although weights were provided by the UAS, the weighting procedure included many variables beyond the ruralurban variable (our primary variable of interest), and the rural-urban variable was downweighted ( $\sim 9 \%$ vs. $\sim 33 \%$ for rural residents; note that US Census data estimates $20 \%$ of the population resides in rural areas (America Counts, 2017)). More information on the construction of data weights in the UAS can be found here: https://uasdata.usc.edu/index.php. Preliminary examination of descriptive statistics and models comparing admiration and resentment of government employees suggested that the unweighted data are virtually identical to the weighted data (see Table S5, Table S6).
} 
largely due to the fact that the difference between admiration and resentment was smaller in rural areas than in mixed or urban areas. Nevertheless, the simple effects indicated that those residing in rural areas $(F(1,3394)=1554.69, p<.001)$, mixed areas $(F(1,3394)=2461.85, p<.001)$ and urban areas $(F(1,3394)=1384, p<.001)$ were all significantly more admiring (rural: $M=1.74$, $S D=.62$; mixed: $M=1.79, S D=.60$; urban: $\mathrm{M}=1.80, \mathrm{SD}=.57$ ) than resentful (rural: $M=.82$, $S D=.45$; mixed: $\mathrm{M}=.77, \mathrm{SD}=.46$; urban: $M=.73, S D=.46$ ) of government employees. Thus admiration is uniformly stronger than resentment, regardless of residence (see Figure S1).

We also conducted a 2 (interior, elite coastal) x 2 (resentment, admiration) mixed-model ANOVA with repeated measures on the second factor. The interaction term was not significant $(F(1,3421)=.42, p=.52)$, indicating no meaningful differences in resentment or admiration between the interior and "elite" coastal states. The simple effects further indicated that people residing both in interior states $(F(1,3421)=4446.03, \mathrm{p}<.001)$ and elite coastal states $(F(1$, $3421)=959.80, \mathrm{p}<.001$ ) were significantly more admiring (interior: $M=1.78, S D=.60$; elite coastal: $M=1.73, S D=.61$ ) than resentful (interior: $M=.79, S D=.46$; elite coastal: $M=.75, S D$ $=.46)$ of government employees. Thus, the difference did not depend upon residence in interior versus elite coastal states of the country (Figure 1, Figure S2).

$$
<<\text { Insert Figure } 1 \text { Here >> }
$$

We further examined the relationship between admiration and resentment and other demographic variables. We estimated a general linear model with education as a continuous between-subjects variable and type of feeling (resentment vs. admiration) as a dichotomous repeated measure. Although the difference between admiration and resentment varied as a function of education, $F(6,3416)=21.96, p<.001$, members of all seven educational categories reported feeling more admiration than resentment of government employees (see Supplementary 
Text S1 for details). Analysis with gender also revealed a significant interaction with type of feeling, $F(1,3422)=55.00, p<.001$. The simple effects suggested that males and females reported more admiration than resentment (male: $F(1,3422)=1891.58, p<.001$; female: $F(1$, $3422)=3655.71, p<.001)$ but the difference between the intergroup emotions was smaller for males (admiration: $M=1.68, S D=.61$; resentment: $M=.79, S D=.47$ ) than for females (admiration: $M=1.85, S D=.58$; resentment: $M=.77, S D=.44$ ). Similarly, analysis with party affiliation indicated a significant interaction with type of feeling, $F(1,2115)=90.06, p<.001$, with the simple effects suggesting that Republicans and Democrats both reported more admiration than resentment (Republican: $F(1,2115)=1239.00, p<.001 ;$ Democrat: $F(1,2115)$ $=2400.85, p<.001$ ) of government employees, but the difference between the intergroup emotions was smaller for Republicans (admiration: $M=1.68, S D=.63$; resentment: $M=.82, S D$ $=.47$ ) than for Democrats (admiration: $M=1.89, S D=.56$; resentment: $M=.72, S D=.45$ ).

Given that the recent rural resentment hypothesis was based on research conducted in the state of Wisconsin (Cramer 2016a, 2016b), we also compared resentment and admiration of Wisconsinites versus the rest of the United States with a 2 (Wisconsin, 49 States) x 2 (resentment, admiration) mixed-model ANOVA with repeated measures on the second factor. Wisconsin was not significantly different from the rest of the United States in level of admiration (WI: $M=1.81, S D=.58$, Median $=2.0$, Min $=0$, Max $=3 ; 49$ States: $M=1.77, \mathrm{SD}=.59$, Median $=1.89$, Min $=0$, Max $=3$ ) or resentment (WI: $M=.85, \mathrm{SD}=.56$, Median $=.67$, Min $=$ .33$, Max $=3.0 ; 49$ states: $M=.78, \mathrm{SD}=.45$, Median $=.67$, Min $=0$, Max $=3), F(1,3422)=.25$, $p=.62$. Although we were underpowered to test our hypotheses only among residents of Wisconsin $(N=117)$, we provide analyses suggesting that living in a rural area of Wisconsin did 
not predict resentment more than living in a rural area of another state (See Supplementary Text S3).

\section{Predictors of Resentment}

Is the small amount of resentment toward government employees explained by the ruralurban divide? We predicted resentment from four social identities (Figure 2, Figure S1, Figure S3) including those associated with rural-urban residence (and interior/coastal residence), party affiliation, educational attainment, gender, and their interactions. Simultaneous regressions revealed that the strongest predictors of resentment toward government employees were lower education levels $(\beta=-.050, \mathrm{SE}=.007, t=-7.31, p<.001)$, and Republican party affiliation $(\beta=$ $.094, \mathrm{SE}=.022, t=4.35, p<.001)$. Neither rural-urban divide $(\beta=-.002, \mathrm{SE}=.014, t=-.15, p=$ $.88)$ nor gender $(\beta=.027, \mathrm{SE}=.022, t=1.28, p=.20)$, and none of their interactions $(p s>.05)$ significantly predicted resentment of government employees (see Table S4). Thus, education level and party affiliation were the strongest predictors of resentment of government employees.

Similar results were obtained from the model containing the interior residence variable (instead of rural-urban), whereby lower education $(\beta=-.053, \mathrm{SE}=.009, t=-6.09, p<.001)$, and Republican party affiliation $(\beta=.150, \mathrm{SE}=.027, t=5.48, p<.000)$ predicted feeling resentment of government employees, but neither interior residence $(\beta=-.030, \mathrm{SE}=.027, t=-1.09, p=.27)$ nor gender $(\beta=.014, \mathrm{SE}=.027, t=.53, p=.60)$ predicted resentment (Table S4). In this model, the interaction of party affiliation and interior residence significantly predicted resentment of government employees $(\beta=-.16, \mathrm{SE}=.055, t=-3.00, p=.003)$, such that Republicans living in elite coastal states $(M=.92, S D=.50)$ self-reported the most resentment and Democrats in elite coastal states $(M=.64, S D=.42)$ reported the least resentment toward government employees, as compared to Republicans $(M=.82, S D=.48)$ and Democrats $(M=.75, S D=.46)$ living in 
interior states (Table S4). Thus, Republicans living in elite coastal states felt the most resentment, and Democrats living in elite coastal states felt the least resentment of government employees.

$<<$ Insert Figure 2 Here $>$

\section{Mediators of Voting Behavior}

Consistent with exit polling, rural Americans were more likely to vote for Donald Trump than for Hillary Clinton in the 2016 general election, $\mathrm{z}=13.48, p<.001$, odds ratio $=1.98$. Thus, rural-urban residence had an effect on voting behavior.

The hypothesis of rural resentment holds that feelings of resentment mediate the relationship between rural-urban residence and voting. We examined this claim by testing a series of mediational analyses (lavaan statistical R package; Rosseel 2012). In a mediation model containing rural-urban residence $(\mathrm{X})$, resentment $(\mathrm{M})$, and voting behavior $(\mathrm{Y})$, the indirect effect through resentment was statistically significant, but represented $5.50 \%$ of the total effect of rural residence on voting behavior (Table 1).

$$
<\text { Insert Table } 1 \text { Here }>>
$$

Because party affiliation and educational attainment are statistically associated with ruralurban residency, their mediating role in the effect of rural residence on voting was also tested. In a mediation model containing rural/urban (X), party affiliation $(\mathrm{M})$, and voting behavior $(\mathrm{Y})$, the indirect effect through party affiliation represents $74.02 \%$ of the total effect of rural-urban on voting behavior. Further, in a model containing rural/urban (X), education (M), and voting behavior (Y), the indirect effect through education represents $12.00 \%$ of the total effect of rural/urban on voting behavior. Thus, the data suggest that resentment does matter to the voting behavior of rural residents in our sample, but less so than political party and education. While 
resentment, party affiliation, and education all mediate the relationship between rural living and voting for Trump (Figure. 3), party affiliation and education represent a greater percentage of the total effect than resentment (Table 1, Figure 3). Similarly, we assessed a mediation model containing interior residence $(\mathrm{X})$, resentment $(\mathrm{M})$, and voting behavior $(\mathrm{Y})$, and found that the indirect effect through resentment was not statistically significant, representing only $5.01 \%$ of the total effect of interior residence on voting behavior (Table 1). Because party affiliation and educational attainment are statistically associated with interior residence, their mediating role in the effect of interior residence on voting was also tested. In a mediation model containing interior residence $(\mathrm{X})$, party affiliation $(\mathrm{M})$, and voting behavior $(\mathrm{Y})$, the indirect effect through party affiliation represented $68.40 \%$ of the total effect of interior residence on voting behavior and was statistically significant. In a model containing interior residence $(\mathrm{X})$, education $(\mathrm{M})$, and voting behavior $(\mathrm{Y})$, the indirect effect through education represented $17.02 \%$ of the total effect of interior residence on voting behavior, and was also significant (Table 1, Figure 3). In other words, education and party affiliation again represent a greater percentage of the total effect of interior residence on voting behavior than resentment (Table 1, Figure 3).

\section{$<<$ Insert Figure 3 Here $>>$}

Further, when we estimated a model with multiple (parallel) mediators, the indirect effect of rural-urban residence through resentment approached zero and was not statistically significant, whereas the indirect effect through party affiliation and education significantly mediated the relationship between rural-urban residence and voting behavior (Figure 4, Table 1). Thus, the data suggest that education and party affiliation mediated the relationship between rural-urban residence and voting behavior, but resentment did not. The same pattern of results was observed in the relationship between interior residence and voting behavior (Figure 4, Table 1). 


\section{$<$ Insert Figure 4 Here $>>$}

We also tested the specific hypothesis that male, less educated, rural residents were most likely to demonstrate resentment-motivated voting in the 2016 US general election. A moderated mediation analysis tested whether resentment mediated the interaction among residence, educational attainment, and gender on voting behavior. Results indicated that the interaction among rural-urban residence, educational attainment, and gender did not significantly predict voting behavior $(\beta=-.039, S E=.042, z=-.938, p=.35)$, and resentment did not mediate this relationship $(\beta=.002, S E=.007, z=0.291, p=.77)$. Similarly, the interaction among interior residence, educational attainment, and gender did not significantly predict voting behavior $(\beta=$ $.024, S E=.081, z=.302, p=.76)$, and resentment $\operatorname{did}$ not mediate this relationship $(\beta=.003, S E$ $=.013, z=.232, p=.82)$.

Together, these results demonstrate that resentment of government employees plays a relatively small role in explaining the effect of rural-urban (or interior) residence, including any interactions of residence with educational attainment and gender, on voting.

\section{Discussion}

Extant research on political psychology links feelings such as anger to behavior associated with political engagement (Valentino et al. 2011). Specific emotions have also been shown to determine individuals' interpretations of political issues. For example, in one study, anxiety about aspects of the Iraq war predicted lower support for involvement in the war (cf. Huddy, Feldman, and Cassese 2007). And individuals' feelings about their current economic situation predicted their evaluations of the government's overall performance and their attention to specific economic concerns (cf. Huddy, Feldman, and Cassese 2007). However, past work has 
not examined the influence of intergroup emotions, such as resentment and admiration, on political behavior.

Our large-scale survey study of a national rural resentment hypothesis and a second survey collected on MTurk/Facebook (see Supplementary Text S1-S3), both of which we derived from recent theory and research on the success of conservative party candidates in the state of Wisconsin (Cramer 2016a, 2016b), revealed surprising results. In particular, Americans in all states and across the rural-urban divide were considerably more admiring than resentful of the three categories of civil servants most often and visibly associated with a so-called urban agenda: public school teachers, public university professors, and agents of departments of natural resource management. In addition, social identities based in party affiliation, educational attainment, and to some extent gender (see Supplementary Text S1), were more predictive of both resentment of government employees and voting behavior than rural-urban or interior residence.

The analyses presented here were conducted using unweighted data. Although one might wonder if conducting our analyses with weighted data would change our main conclusions about feelings of admiration being greater than resentment of government employees, an examination of Table S5 indicates that the weighted and unweighted means are virtually identical. Further, Table S6 shows that admiration of government employees is significantly higher than resentment at the aggregate and across all demographic groups of interest in analyses conducted with the weighted and unweighted data.

Further, as no formal definitions of "elite coastal" versus "interior" states exist, we identified these based on mainstream perceptions of what regions of the US are more "elite" versus constitute the "flyover" country (Baldassarri and Gelman, 2008; Barrick, Lavoie, and 
Haverty 2016; Harkins 2016; Townsend 2016; Vance 2016a, 2016b), and so other classifications may be possible. It should also be noted that the interior vs. "elite" coastal variable is not a direct proxy of the rural-urban measure, as major metropolitan areas (e.g., Chicago, Houston) exist in many of the interior states. However, as described above, the interior versus "elite" coastal state divide provides another way to capture residence-based "us" versus "them" perceptions.

Further, in the present research we only collected measures of resentment toward three groups of state employees - public school teachers, university professors, and agents of departments of natural resource management - and one specific outcome measure - voting in presidential elections. In addition, the present research asked about specific government employees, which is different than asking about the government at large, elite members of society, or about specific agencies/institutions (e.g., public school districts, the department of natural resources, or the state flagship university, generally). It is plausible that imagining an individual who is a member of such an organization makes that individual seem more relatable, which may have heightened admiration and reduced resentment in the present research. Future research should examine how resentment toward a variety of groups, as well as more generally toward elite socioeconomic classes, government agencies, and/or institutions, is related to a variety of political outcomes, such as specific policy issues of current importance or past voting behavior.

The rural resentment hypothesis was derived from research involving extensive testimonies collected in group discussions (e.g., Cramer 2016a) and is implied by reports of a national rural-urban polarization. The fact that both our main survey study and another survey collected on MTurk/Facebook (see Supplementary Text S1-S3) did not provide strong support for this hypothesis could be due to differences in methodology. Interview methods are 
irreplaceable sources of information for generating hypotheses about the state of public opinion (Cramer 2016a, 2016b). However, they may involve a limited number of interviewers and small or non-representative samples. Moreover, attitudes expressed in the context of group discussion are notably different than those held privately (Brauer, Judd, and Jacquelin 2001) and therefore may have a different relationship to voting behavior. Individuals can be queried about emotions related to outgroups as well as their voting behavior using survey methodology (Feather and Sherman 2002). In fact, self-report on standardized questionnaires is the method that has been most often used to study emotions towards outgroups (Mackie and Smith 2015; Tam et al. 2007). Neither physiological nor facial expression analysis is likely to provide a more reliable assessment of resentment or admiration than self-report.

Importantly, our findings suggest that in the absence of a prime indicating that resentment toward state workers is appropriate, we observe minimal resentment and far greater admiration than resentment. It is possible that the qualitative research on the rural resentment hypothesis activated previous information about government workers having unfair benefits, and this boosted self-reported feelings of resentment and increased the impact that resentment seemingly had on voting behavior. Indeed, this kind of primed information is often used by political candidates to leverage support during campaigns.

The present research complements and extends the existing qualitative work by providing an empirical analysis across the United States and suggests that educational attainment, party affiliation, and to some extent gender, are more important than geographic residence in accounting for political voting behavior, and that the small effect of urban versus rural residence on voting behavior cannot be explained by resentment toward government employees. 


\section{Acknowledgements}

The authors thank Norbert Schwarz for his feedback during the development of our US Feelings survey, Janet Hyde, Jon Krosnick, Jon Pevehouse, and Eliot Smith for their insightful feedback on this research and the manuscript, and Fangyun Zhao for assistance with data visualization.

Funding details: S.M.C. was supported by the National Institute of Mental Health of the National Institutes of Health under Award T32MH018931. P.M.N. was supported by an award from the Wisconsin Alumni Research Foundation. Data availability statement: The two data files and survey materials used in this research will be fully available upon publication.

\section{Disclosure statement}

Authors declare no conflicts of interest or benefit that has arisen from the direct applications of this research.

\section{References}

Algoe, Sara B., and Jonathan Haidt. 2009. "Witnessing excellence in action: The 'other-praising' emotions of elevation, gratitude, and admiration." The Journal of Positive Psychology 4 (2): 105127.

America counts. 2017. "One in five Americans live in rural areas." United States Census Bureau. Retrieved at: https://www.census.gov/library/stories/2017/08/rural-america.html.

Baldassarri, Delia, and Andrew Gelman. 2008. "Partisans without constraint: Political polarization and trends in American public opinion." American Journal of Sociology 114 (2): 408-446.

Barrick, Dan, Rebecca Lavoie, and Natasha Haverty. 2016. "As New Hampshire Shifts to a Swing State, Why Do Legislative Lines Still Favor Republicans?" New Hampshire Public Radio. 
Retrieved at: https://www.nhpr.org/post/new-hampshire-shifts-swing-state-why-do-legislativelines-still-favor-republicans\#stream/0.

Berelson, Bernard R., Paul F. Lazarsfeld, and William N. McPhee. 1954. Voting: A Study of Opinion Formation in a Presidential Campaign. Chicago: University of Chicago Press.

Brauer, Markus, Charles M. Judd, and Vincent Jacquelin. 2001. "The communication of social stereotypes: The effects of group discussion and information distribution on stereotypic appraisals." Journal of Personality and Social Psychology 81 (3): 463-475.

Brown, Rupert. 2000. "Social identity theory: Past achievements, current problems and future challenges." European Journal of Social Psychology 30 (6): 745-778.

Brownstein, Ronald. 2008. The Second Civil War: How Extreme Partisanship Has Paralyzed Washington and Polarized America. New York: Penguin.

Cramer, Katherine J. 2016a. The Politics of Resentment: Rural Consciousness in Wisconsin and the Rise of Scott Walker. Chicago: University of Chicago Press.

Cramer, Katherine J. 2016b. "The turn away from government and the need to revive the civic purpose of higher education." Perspectives on Politics 14 (2): 442-450.

Druckman, James N., Erik Peterson, and Rune Slothuus. 2013. "How elite partisan polarization affects public opinion formation." American Political Science Review 107 (1): 57-79.

Ekman, Paul. 1993. "Facial expression and emotion." American Psychologist 48 (4): 384-392.

Ellemers, Naomi, Paulien Kortekaas, and Jaap W. Ouwerkerk. 1999. "Self-categorisation, commitment to the group and group self-esteem as related but distinct aspects of social identity." European Journal of Social Psychology 29 (2-3): 371-389. 
Feather, Norman T., and Rebecca Sherman. 2002. "Envy, resentment, schadenfreude, and sympathy: Reactions to deserved and undeserved achievement and subsequent failure." Personality and Social Psychology Bulletin 28 (7): 953-961.

Fiorina, Morris P., and Matthew S. Levendusky. 2006. "Disconnected: The political class versus the people." Red and Blue Nation 1: 49-71.

Gimpel, James G., and Jason E. Schuknecht. 2009. Patchwork Nation: Sectionalism and Political Change in American Politics. Ann Arbor: University of Michigan Press.

Haidt, Jonathan. 2003. "The moral emotions." In Handbook of Affective Sciences, edited by R. J. Davidson, K. R. Scherer, and H. H. Goldsmith: 852-870. Oxford: Oxford University Press. Harkins, Anthony. 2016. "The Midwest and the Evolution of "Flyover Country"." Middle West Review 3 (1): 97-121.

Hogg, Michael A. 2013. "Intergroup relations." In Handbook of Social Psychology, edited by J. DeLamater, and A. Ward, 533-561. Philadelphia: Springer Science and Business Media. Huddy, Leonie, Stanley Feldman, and Erin Cassese. 2007. "On the Distinct Political Effects of Anxiety and Anger." In The Affect Effect: Dynamics of Emotion in Political Thinking and Behavior, edited by G. E. Marcus, W. R. Neuman, M. MacKuen, and A. N. Crigler: 202-230. Chicago: University of Chicago Press.

Inglehart, Ronald, and Pippa Norris. 2000. "The developmental theory of the gender gap: Women's and men's voting behavior in global perspective." International Political Science Review 21 (4): 441-463.

Jackson, John E. 1975. "Issues, party choices, and presidential votes." American Journal of Political Science 19: 161-185. 
Judd, Charles M., McClelland, Gary H., and Ryan, Carey S. 2017. Data Analysis: A ModelComparison Approach. $3^{\text {rd }}$ Edition. New York: Routledge.

Kawakami, Kerry, and Kenneth L. Dion. 1993. "The impact of salient self-identities on relative deprivation and action intentions." European Journal of Social Psychology 23 (5): 525-540.

Kinder, Donald R., and Lynn M. Sanders. 1996. Divided by color: Racial Politics and Democratic Ideals. Chicago: University of Chicago Press.

Mackie, Diane M., and Eliot R. Smith. 2015. "Intergroup emotions." In APA Handbook of Personality and Social Psychology, edited by M. Mikulincer, and P. R. Shaver, 2: 263-293. Washington D.C.: American Psychological Association.

Mackie, Diane M., and Eliot R. Smith. 2018. "Intergroup emotions theory: Production, regulation, and modification of group-based emotions." Advances in Experimental Social Psychology 58: 169.

Mackie, Diane M., Eliot R. Smith, and Devin G. Ray. 2008. "Intergroup emotions and intergroup relations." Social and Personality Psychology Compass 2 (5): 1866-1880.

McCarty, Nolan, Keith T. Poole, and Howard Rosenthal. 2006. Polarized America: The Dance of Ideology and Unequal Riches. Cambridge: MIT Press.

Milligan, Kevin, Enrico Moretti, and Philip Oreopoulos. 2004. "Does education improve citizenship? Evidence from the United States and the United Kingdom." Journal of Public Economics 88 (9-10): 1667-1695.

Nicholson, Stephen P. 2012. "Polarizing cues." American Journal of Political Science 56 (1): 52-66. Oveis, Christopher, Elizabeth J. Horberg, and Dacher Keltner. 2010. "Compassion, pride, and social intuitions of self-other similarity." Journal of Personality and Social Psychology 98 (4): 618630. 
Page, Benjamin I., and Calvin C. Jones. 1979. "Reciprocal effects of policy preferences, party loyalties and the vote." American Political Science Review 73 (4): 1071-1089.

Rosseel, Yves. 2012. "Lavaan: An R package for structural equation modeling and more. Version 0.5-12 (BETA)." Journal of Statistical Software 48 (2): 1-36.

Rozin, Paul, Jonathan Haidt, and Clark R. McCauley. 1999. "Disgust: The body and soul emotion." In Handbook of Cognition and Emotion, edited by T. Dalgleish, and M. J. Power: 429-445. New York: Wiley.

Smith, Eliot R. 1993. "Social identity and social emotions: Toward new conceptualizations of prejudice." In Affect, Cognition and Stereotyping, edited by D. M. Mackie, and D. L. Hamilton: 297-315. San Diego: Academic Press.

Smith, Heather J., Russell Spears, and Intse J. Hamstra. 1999. "Social identity and the context of relative deprivation." In Social Identity: Content, Commitment, Context, edited by N. Ellemers, R. Spears, and B. Doosje: 205-229. Oxford: Blackwell Science.

Stangor, Charles. 2004. Social Groups in Action and Interaction. New York: Psychology Press. Tajfel, Henri and John C. Turner. 1986. "The social identity theory of intergroup behavior." Psychology of Intergroup Relations 5: 7-24.

Tam, Tania, Miles Hewstone, Ed Cairns, Nicole Tausch, Greg Maio, and Jared Kenworthy. 2007. "The impact of intergroup emotions on forgiveness in Northern Ireland." Group Processes \& Intergroup Relations 10 (1): 119-136.

Townsend, Duane. 2016. "American is held hostage by flyover states." The Hill 12. Retrieved at: http://thehill.com/blogs/pundits-blog/the-administration/310054-america-is-held-hostage-byflyover-states. 
Valentino, Nicholas A., Ted Brader, Eric W. Groenendyk, Krysha Gregorowicz, and Vincent L. Hutchings. 2011. "Election night's alright for fighting: The role of emotions in political participation." The Journal of Politics 73 (1): 156-170.

Vance, J. D. 2016a. “The coasts and the 'flyover country' - the great US divide.” The Standard 10. Retrieved at: http://www.standard.co.uk/comment/comment/the-coasts-and-the-flyover-countrythe-great-us-divide-a3381306.html.

Vance, J. D. 2016b. "Life outside the liberal bubble." New York Times 11. Retrieved at: https://www.nytimes.com/interactive/projects/cp/opinion/election-night-2016/life-outside-theliberal-bubble. 
Table 1. Mediators of rural residence on likelihood of voting for Trump over Clinton. Indirect effects of rural and interior living through feelings of resentment, party affiliation, and education (models 1-6 contain individual mediators, models 7-8 contain parallel mediators), on the likelihood of voting for Trump over Clinton. Coefficients are unstandardized.

\begin{tabular}{|c|c|c|c|c|c|}
\hline $\begin{array}{c}\text { Model } \\
\mathrm{Nr}\end{array}$ & $\begin{array}{l}\text { Distant } \\
\text { Cause } \\
\text { (X) }\end{array}$ & $\begin{array}{l}\text { Proximal } \\
\text { Cause } \\
\text { (M) }\end{array}$ & $\begin{array}{c}\text { Indirect } \\
\text { Effect } \\
(\mathrm{ab})\end{array}$ & $\begin{array}{l}\text { Total } \\
\text { Effect } \\
\text { (c) }\end{array}$ & $\begin{array}{l}\text { Per- } \\
\text { cent } \\
(\mathrm{ab} / \mathrm{c})\end{array}$ \\
\hline \multicolumn{6}{|c|}{ Individual Mediators } \\
\hline 1 & Rural & Resentment & $.022 * *[.007]$ & $.400 * *[.032]$ & $5.50 \%$ \\
\hline 2 & Rural & Party Affil. & $.322 * *[.035]$ & $.435 * *[.037]$ & $74.02 \%$ \\
\hline 3 & Rural & Education & $.051 * *[.007]$ & $.425 * *[.031]$ & $12.00 \%$ \\
\hline 4 & Interior & Resentment & $.019[.012]$ & $.379 * *[.060]$ & $5.01 \%$ \\
\hline 5 & Interior & Party Affil. & $.303 * *[.064]$ & $.443 * *[.068]$ & $68.40 \%$ \\
\hline 6 & Interior & Education & $.064 * *[.012]$ & $.376 * *[.057]$ & $17.02 \%$ \\
\hline \multicolumn{6}{|c|}{ Parallel Mediators } \\
\hline 7 & Rural & Resentment & $.004[.003]$ & $.413 * *[.039]$ & $0.97 \%$ \\
\hline 7 & Rural & Party Affil. & $.298 * *[.036]$ & $.413 * *[.039]$ & $72.15 \%$ \\
\hline 7 & Rural & Education & $.020 * *[.006]$ & $.413 * *[.039]$ & $4.84 \%$ \\
\hline 8 & Interior & Resentment & $.006[.004]$ & $.452 * *[.072]$ & $1.33 \%$ \\
\hline 8 & Interior & Party Affil. & $.315 * *[.066]$ & $.452 * *[.072]$ & $69.69 \%$ \\
\hline 8 & Interior & Education & $.028 * *[.008]$ & $.452 * *[.072]$ & $6.19 \%$ \\
\hline
\end{tabular}




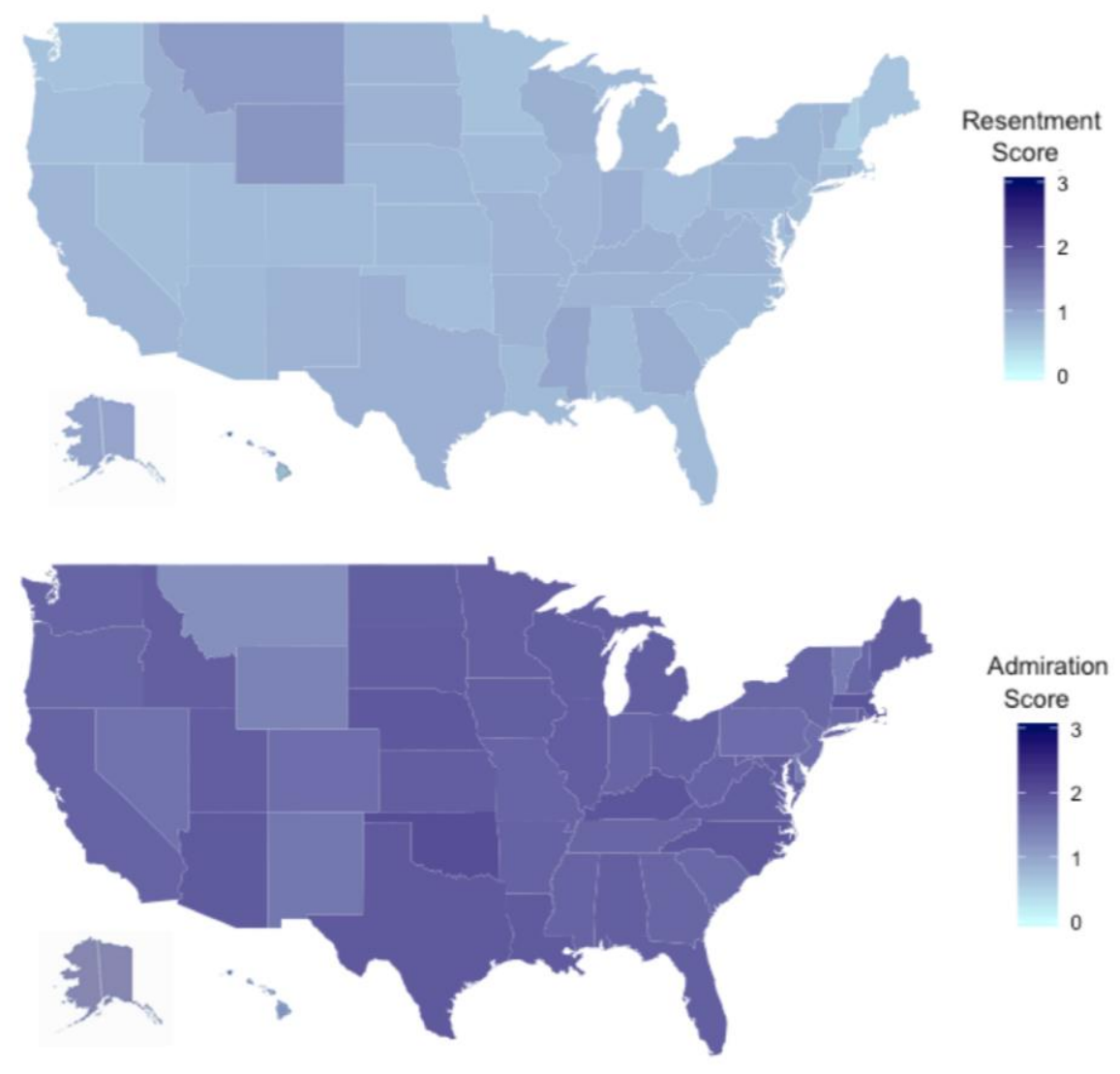

Figure 1. Resentment and admiration across the United States. Resentment (top panel) toward groups of government employees (school teachers, university professors, and agents of offices of natural resource management) was significantly lower than admiration (bottom panel). This difference did not vary as a function of living in elite coastal states versus the interior of the United States. See Figure S2 for another visualization of the comparison of admiration and resentment across the United States. 

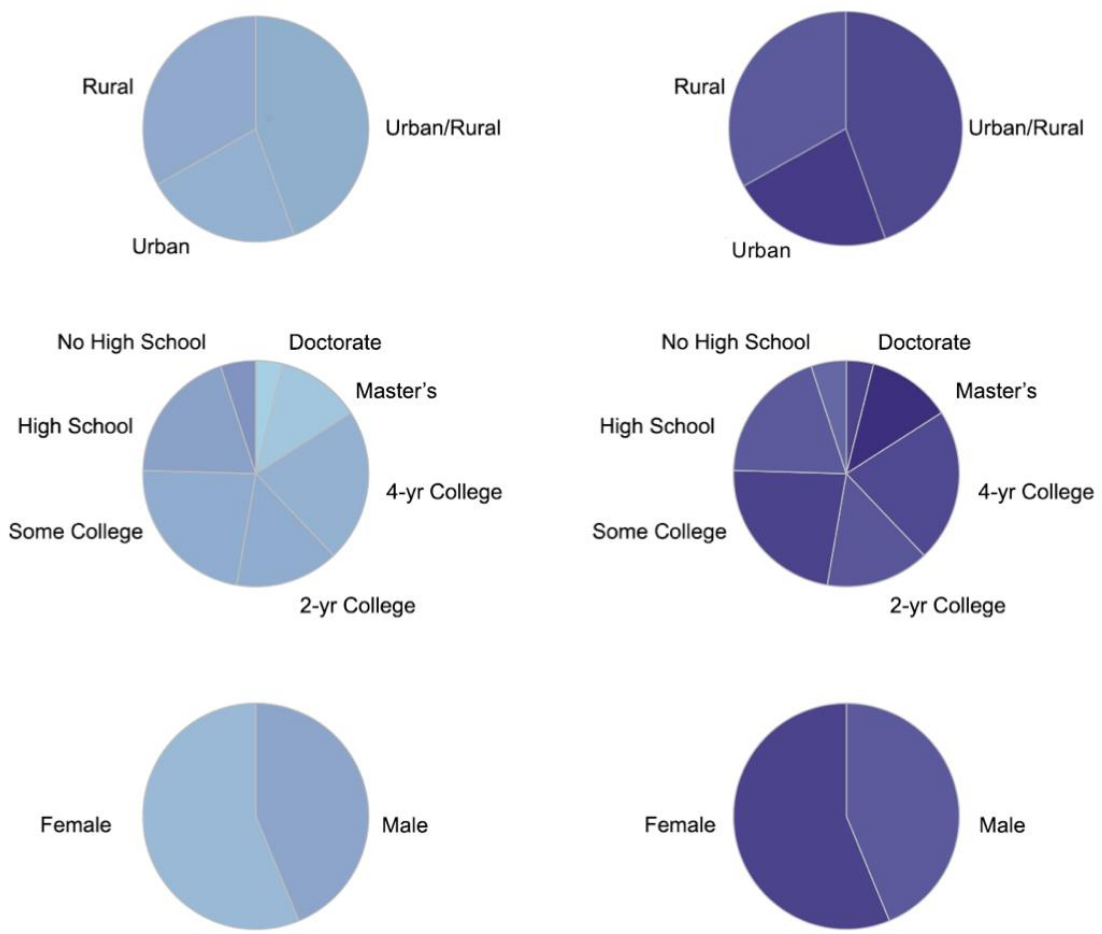

Resentment Score
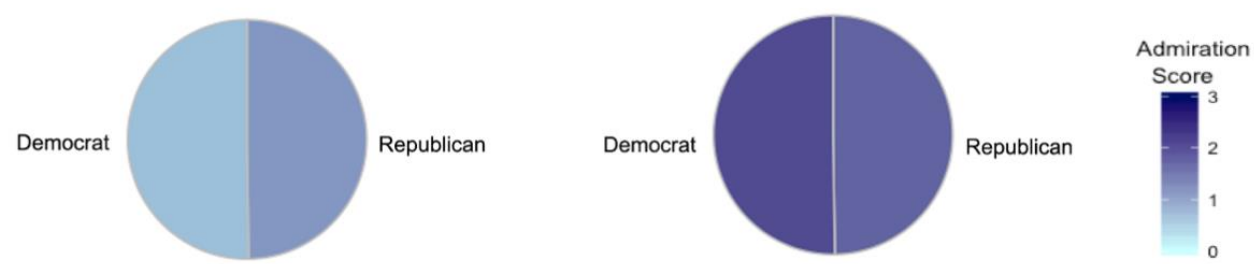

Figure 2. Resentment and admiration by demographic groups. The size of each pie piece represents the relative sample size of each emotion category. Color represents the extent to which respondents felt resentment (left panel) and/or admiration (right panel). See Figures S1 and S3 for another visualization of the comparison of admiration and resentment across demographic categories. 

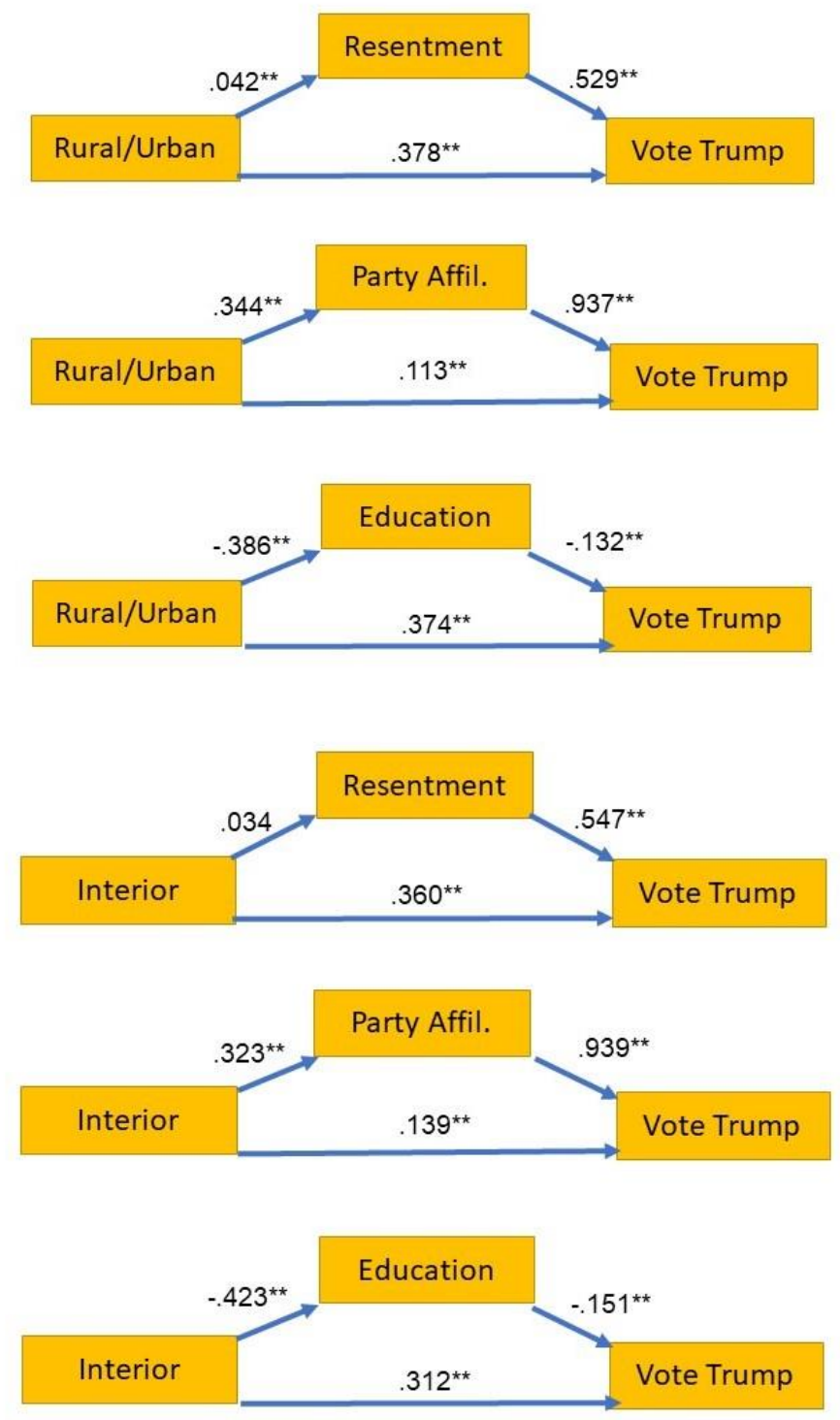

Figure 3. Resentment, party affiliation, and education in voting. Representation of a series of mediational models. Coefficients are unstandardized. Findings reveal significant partial mediation by resentment, party affiliation, and education of rural residence on voting. Coding of the variables was as follows: urban/rural classification, $0=$ urban, $1=$ mixed urban/rural, $2=$ rural; state of residence, $0=$ elite coastal state, $1=$ interior state; education, $1=$ lowest, $7=$ highest , treated as a continuous variable; party affiliation, $0=$ Democrat, $1=$ Republican. ${ }^{*} p<.05$, ** $p<$ 0.01 level (2-tailed). See Supplementary Text S2 for details. 

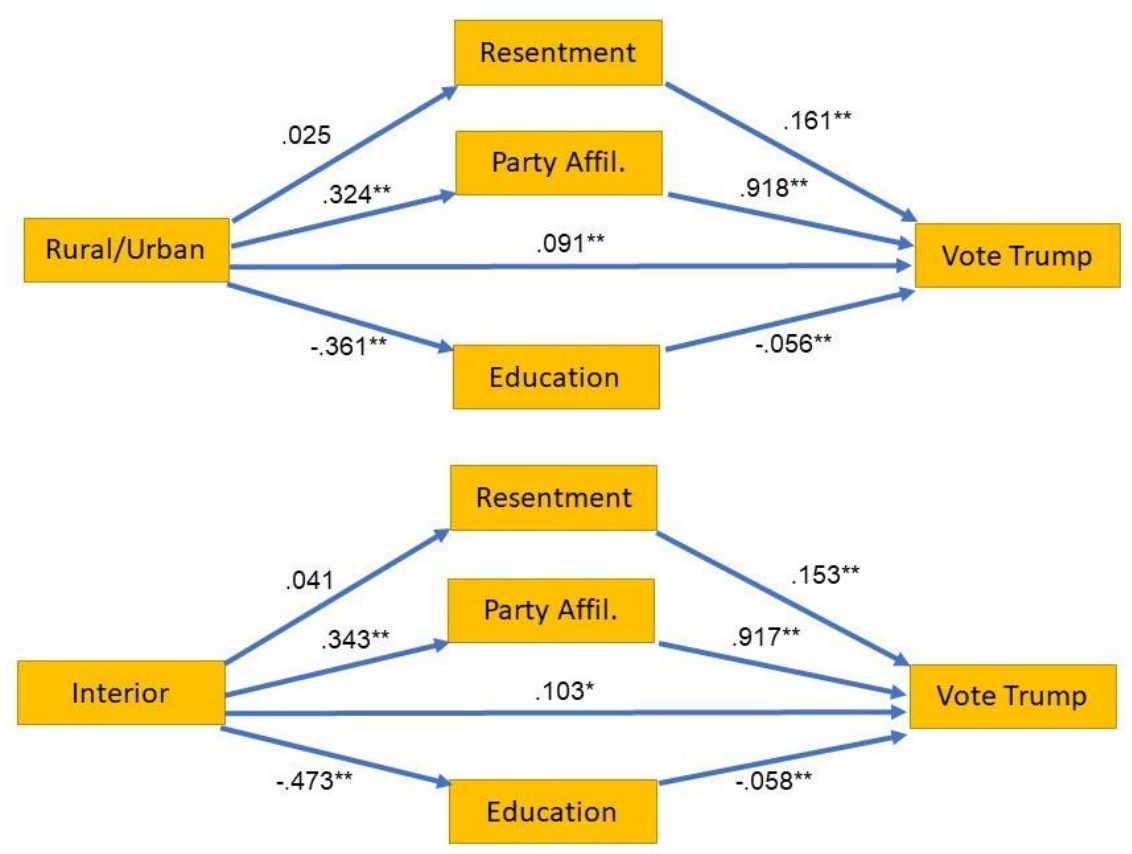

Figure 4. Resentment, party affiliation, and education as parallel mediators in voting. Representation of mediational models. Coefficients are unstandardized. Findings reveal significant partial mediation by party affiliation and education of rural residence on voting, but not resentment. Coding of the variables was as follows: urban/rural classification, $0=$ urban, $1=$ mixed urban/rural, 2 = rural; state of residence, 0 = elite coastal state, $1=$ interior state; education, $1=$ lowest, $7=$ highest, treated as a continuous variable; party affiliation, $0=$ Democrat, $1=$ Republican. ${ }^{*} p<.05, * * p<0.01$ level (2-tailed). See Supplementary Text S2 for details. 


\section{Did Rural Resentment of Government Employees Elect Donald Trump? Supplemental Information}

\section{Supplementary Text 1}

This section primarily reports methodological details and results of the study using a combined Amazon Mechanical Turk (MTurk) and Facebook sample (referred to throughout as the MTurk/Facebook sample) that was collected prior to the UAS sample reported in the main text. In addition, some results from the UAS sample are also reported here.

\section{Overview of Results in MTurk/Facebook Sample}

The results we obtained from a national MTurk/Facebook sample yielded very similar results to those reported in our main UAS sample (see Supplementary Text S1-S3, Tables S1, S3, S7-S9, for detailed information). One difference was that when we predicted resentment from the four social identities (political party affiliation, education, residence, and gender) in the MTurk/Facebook sample, Republican party affiliation $(\beta=.226, \mathrm{SE}=.037, t=6.13, p<.001)$, identifying as a male $(\beta=.225, \mathrm{SE}=.037, t=6.10, p<.001)$, and lower education level $(\beta=-$ $.042, \mathrm{SE}=.017, t=-2.48, p=.013)$ predicted feeling resentment toward government employees, and interior residence $(\beta=-.064, \mathrm{SE}=.037, t=-1.73, p=.084)$ did not (Table S8).

In line with the main UAS sample, the interaction of party affiliation and interior residence again significantly predicted resentment of government employees $(\beta=-.200, \mathrm{SE}=$ $.074, t=-2.71, p=.007)$, where Republicans living in coastal states $(M=.58, \mathrm{SD}=.75)$ selfreported the most resentment and Democrats in coastal states $(M=.27, \mathrm{SD}=.45)$ reported the least resentment toward government employees, as compared to Republicans $(M=.45, \mathrm{SD}=.62)$ and Democrats $(M=.30 \mathrm{SD}=.49)$ living in interior states. 
One possible concern is the representativeness of a sample collected primarily through MTurk. Despite the limitations of collecting data online for payment (MTurk; Chang and Krosnick 2009; Yeager et al. 2011), MTurk samples have been shown to be more representative of the United States population than convenience samples (Berinsky, Huber, and Lenz 2012). Some research has indicated that probability samples, such as the UAS sample used in the analyses reported above, are more representative than MTurk (Berinsky et al., 2012). However, more recent research directly comparing MTurk samples to the Cooperative Congressional Election Survey (CCES), an annual nationally stratified sample that collects information on political attitudes, voter choice, and demographics, suggested that MTurk and the CCES collect very similar samples in terms of the demographic categories of occupation and rural-urban residence (Huff and Tingley 2015). This suggests that researchers interested in the rural-urban divide should not be concerned that MTurk respondents are non-representative in terms of geographic location, compared to professionally polled surveys (i.e., CCES or UAS).

\section{MTurk/Facebook Sample, Survey and Procedure}

A national sample of respondents $(N=2280)$ was recruited through advertisements on MTurk and Facebook (i.e., the MTurk/Facebook sample) to complete a "US Feeling Survey." Data collection ran from January 19th through February 7th, 2017, and sample size was determined by the number of participants who responded to the survey within this time-period. Respondents on Mechanical Turk were compensated $\$ .50$ for completing the survey, and those on Facebook volunteered their time. Eight respondents were not currently living in the United States and were excluded from analyses, leaving a sample of 2272 respondents (1107 females) for analysis. 
The United States Feeling Survey assessed respondents' feelings toward government employees of their current state of residence. Respondents first rated, on scales ranging from 0 (not at all) to 3 (very much), the degree to which the members of three categories of government employees made them feel each of nine different feeling states (i.e., resentment emotions: anger, resentment, disgust; admiration emotions: pride, admiration, gratefulness; negative filler emotions: fear, shame, jealousy). These questions and rating scales were the same as in the UAS sample described in the main text. However, the US Feeling Survey administered to the MTurk/Facebook sample was not translated into Spanish.

The groups of government employees evaluated were again public school teachers, university professors at the state's flagship (i.e., major public) institution(s), and agents of their state's natural resource agency (e.g., Department of Natural Resources). Respondents in the US Feeling Survey MTurk/Facebook sample also rated their feelings (using the nine emotion adjectives listed above) about the two major party presidential candidates (Trump and Clinton).

Respondents also reported their vote in the 2016 election, rated their mood over the past month using the Brief Mood Introspection Scale (BMIS; Mayer \& Gaschke, 1988; Note: the BMIS was administered in this US Feeling Survey MTurk/Facebook sample only), and completed demographic questions. A complete list of demographics, including frequencies by state, gender, political party affiliation, education, age, and race/ethnicity are reported Table S1. Analyses of feelings toward the candidates, responses to the BMIS, and demographic analyses of gender, age, and ethnicity are part of a separate report and will not be considered further.

\section{Coding of Variables}


Interior versus "elite" coastal states. We again generated a binary variable reflecting residence in "elite" coastal (0) or interior (1) state, using the same procedure as in the UAS sample.

Rural versus urban residence. For respondents in the MTurk/Facebook Sample, we did not have access to United States census data on rural versus urban classification.

Educational attainment, party affiliation, and gender. The correlations among educational attainment, party affiliation, and gender are reported in Table S3. The coding for demographic variables for the MTurk/Facebook sample can be found in the captions of Figure S4 and Figure S5. For analyses containing interaction terms, all predictor variables were mean centered.

Voting in the 2016 general election. Based on exit polling and qualitative interview findings (1), we expected voting in the 2016 US general election to be predicted by interior versus elite coastal states as well as gender, educational attainment, and party affiliation. For all analyses, we used as the dependent measure a binary vote variable to represent voting for Clinton (0) and Trump (1). Participants who did not vote or who voted for other candidates were excluded from analyses (see Table S1).

\section{Results}

\section{Feelings About Government Employees}

Cronbach's alphas comparing each emotion adjective across the three categories of government employees, were high for all nine emotions, and ranged from $\alpha=.662$ to $.774,(M=$ $.717, S D=.03)$. Respondents reported a moderate degree of pride $(M=1.69, S D=.81)$, admiration $(M=1.75, S D=.80)$, and gratefulness $(M=1.81, S D=.81)$ and a slight degree of resentment $(M=.33, S D=.57)$, anger $(M=.33, S D=.58)$, and disgust $(M=.38, S D=.60)$. They 
also reported a slight degree of other negative emotions that were not part of a resentment index but were added to distract from our specific interests: fear $(M=.22, S D=.50)$, shame $(M=.28$, $S D=.55)$, and jealousy $(M=.22, S D=.47)$ toward government employees.

Calculation of resentment and admiration indices. We computed a theoretically driven resentment index for the MTurk/Facebook sample by averaging the other-condemning emotions (i.e., resentment, anger, and disgust; Cronbach's $\alpha=.906$; see emotion intercorrelations: Table S9). Similarly, we computed a theoretically driven admiration index by averaging the three other-praising emotions (i.e., admiration, pride, and gratefulness; Cronbach's $\alpha=.905$; see emotion intercorrelations: Table S9).

Relationships between resentment and admiration. We computed bivariate correlations between the two feeling indices. As in the UAS sample reported in the main text, correlations were negative but small, $r=-.320, p<.001$ in the MTurk/Facebook sample. Thus, the two intergroup emotions are not simply opposites and it is sensible to compare the levels of both feelings toward government employees.

\section{Predictors of Resentment}

The interior versus "elite" coastal state divide. We compared levels of resentment and admiration toward government employees as a function of residence in interior versus so-called "elite" coastal states of the United States. A 2 (interior, elite coastal) x 2 (resentment, admiration) mixed-model ANOVA with repeated measures on the second factor revealed no interaction between admiration and resentment emotions and residence in interior versus elite states $(F(1$, $2218)=.20, p=.66)$. The simple effects indicated that people living in interior states $(F(1,2218)$ $=2924.42, \mathrm{p}<.001)$ and elite coastal states $(F(1,2218)=1141.17, \mathrm{p}<.001)$ were both 
significantly more admiring (interior: $M=1.76, S D=.75$; elite coastal: $M=1.73, S D=.73$ ) than resentful (interior: $M=.34, S D=.52$; elite coastal: $M=.34, S D=.54$ ) of government employees. Other demographic variables. Results again showed a significant interaction between feelings of resentment and admiration of government employees and education level $(F(5,2222)$ $=6.78, p<.001$ ). The simple effects indicated that admiration (less than high school: $M=1.14$, $S D=.86$; high school: $M=1.69, S D=.77 ; 2$-year college: $M=1.67, S D=.78 ;$ 4-year college: $M=1.77, S D=.72 ;$ master's: $M=1.93, S D=.66$; doctorate $-\mathrm{PhD}$ or professional degree: $M=$ $1.82, S D=.74$ ) was significantly greater than resentment (less than high school: $M=.79, S D=$ .74 ; high school: $M=.35, S D=.54 ; 2$-year college: $M=.37, S D=.56 ; 4$-year college: $M=.34$, $S D=.53$; master's: $M=.29, S D=.45$; doctorate $-\mathrm{PhD}$ or professional degree: $M=.29, S D=$ $.52)$ of government employees for all educational categories except for less than high school (less than high school: $F(1,2222)=1.39, p=.24$; high school: $F(1,2222)=953.85, p<.001 ; 2-$ year college: $F(1,2222)=603.00, p<.001 ; 4$-year college: $F(1,2222)=1740.10, p<.001$; master's: $F(1,2222)=651.79, p<.001$; doctorate $-\mathrm{PhD}$ or professional degree: $F(1,2222)=$ $182.28, \mathrm{p}<.001)$

We also conducted a 2 (male, female) x 2 (resentment, admiration) mixed-model ANOVA with repeated measures on the second factor. There was a reliable interaction between admiration and resentment of government employees and gender, $F(1,2217)=75.21, p<.001$. Although both male and female respondents reported significantly more admiration than resentment (male: $F(1,2217)=1620.33, p<.001$; female: $F(1,2217)=2673.94, p<.001)$, this difference was somewhat smaller for males (admiration: $M=1.64, S D=.75$; resentment: $M=$ $.41, S D=.59$ ) than for females (admiration: $M=1.87, S D=.70$; resentment: $M=.27, S D=.45$ ). 
Finally, results of a 2 (Republican, Democrat) x 2 (resentment, admiration) mixed-model ANOVA with repeated measures on the second factor revealed a significant interaction between admiration and resentment of government employees and party affiliation, $F(1,1298)=69.60, p$ $<.001$. Although both Republican and Democrat respondents reported significantly more admiration than resentment (Republican: $F(1,1298)=481.15, p<.001$; Democrat: $F(1,1298)=$ 2232.42, $p<.001$ ), this difference was somewhat smaller for Republicans (admiration: $M=1.59$, $S D=.74$; resentment: $M=.48, S D=.66$ ) than for Democrats (admiration: $M=1.90, S D=.69$; resentment: $M=.29, S D=.48)$.

UAS sample education means. The simple effects in the UAS sample indicated that admiration (less than high school: $M=1.57, S D=.63$; high school: $M=1.72, S D=.62$; Some college: $M=1.78, S D=.60 ; 2$-year college: $M=1.76, S D=.59$; 4-year college: $M=1.78, S D=$ .58 ; master's: $M=1.90, S D=.55$; doctorate $-\mathrm{PhD}$ or professional degree: $M=1.79, S D=.61$ ) was significantly greater than resentment (less than high school: $M=.96, S D=.48$; high school: $M=.90, S D=.48$; Some college: $M=.81, S D=.47 ; 2$-year college: $M=.80, S D=.45 ;$-year college: $M=.70, S D=.42$; master's: $M=.66, S D=.42 ;$ doctorate $-\mathrm{PhD}$ or professional degree: $M=.61, S D=.40$ ) of government employees for all educational categories (less than high school: $F(1,3416)=97.64, p<.001$; high school: $F(1,3416)=720.04, p<.001$; Some college: $F(1,3416)=1199.98, p<.001 ; 2$-year college: $F(1,3416)=785.42, p<.001$; 4-year college: $F(1,3416)=1507.88, p<.001$; master's: $F(1,3416)=1093.14, p<.001$; doctorate $-\mathrm{PhD}$ or professional degree: $F(1,3416)=331.41, p<.001)$.

\section{Mediators of Voting Behavior}

Consistent with findings from analysis of the UAS sample reported in the main text, Americans living in the interior states were more likely to vote for Trump than those who lived 
in the elite coastal states $\mathrm{z}=2.40, p=.018$, odds ratio $=1.33$. Interior residence thus had an effect on voting behavior.

Mediational models showed that the effect of interior residence on voting was not significantly mediated by resentment, which only accounted for $1.10 \%$ of the total effect of interior residence on voting (Figure S4; Table S7). When we estimated a model with multiple (parallel) mediators, the indirect effect through resentment was again very small $(1.12 \%)$ and not-significant, whereas the indirect effect through party affiliation (121.35\%) was significant. The indirect effect through educational attainment was also non-significant (3.93\%) in the parallel mediation model (Figure S5, Table S7).

Finally, we tested the specific hypothesis that male, less educated, rural residents were most likely to demonstrate resentment-motivated voting in the 2016 US general election. A moderated mediation analysis tested whether resentment mediated the interaction between residence, educational attainment, and gender on voting behavior. Results indicated that the interaction, as in the previous analysis, again did not significantly predict voting $(\beta=.069, S E=$ $.139, z=.497, p=.62)$, and resentment did not mediate this relationship $(\beta=-.021, S E=.029, z$ $=-.721, p=.47)$.

These results further demonstrate that resentment plays a minor role in explaining the effect of interior residence, including any interactions of residence with educational attainment and gender, on voting. 


\section{Supplementary Text S2}

\section{Complete details of mediation models in the Understanding America Study (UAS) and MTurk/Facebook samples.}

For each analysis presented below, we entered the relevant demographic characteristic (rural or interior) as the predictor variable $(\mathrm{X})$, resentment toward government employees, party affiliation, and/or education as the mediators $\left(\mathrm{M}_{1}, \mathrm{M}_{2}\right.$, and $\left.\mathrm{M}_{3}\right)$ and voting behavior (Trump vs. Clinton) as the dependent variable (Y).

\section{Rural versus Urban Classification (UAS Sample Only).}

The first demographic characteristic of interest was rural-urban residence. We tested the hypothesis that resentment, party affiliation, and education would mediate the relationship between living in a rural versus urban setting and the likelihood of voting for Trump in the UAS sample only.

\section{Parallel Mediators}

The effect of living in a rural or urban setting on resentment toward government employees $(\beta=.025, \mathrm{SE}=.014, z=1.74, p=.082)$ was not significant, but on party affiliation $(\beta$ $=.324, \mathrm{SE}=.039, z=8.42, p<.001)$ and education $(\beta=-.361, \mathrm{SE}=.047, z=-7.69, p<.001)$ were statistically significant (Figure 4). When examining the partial effects of the predictor variable and the mediators on the dependent variable, rural versus urban living $(\beta=.091, \mathrm{SE}=$ $.027, z=3.39, p<.001)$, resentment toward government employees $(\beta=.161, \mathrm{SE}=.041, z=$ $3.89, p<.001)$, party affiliation $(\beta=.918, \mathrm{SE}=.010, z=95.95, p<.001)$, and education $(\beta=-$ $0.056, \mathrm{SE}=.013, z=-4.22, p<.001)$ were all statistically significant. The indirect effects of rural versus urban living through feelings of resentment was not significant $(\beta=.004, \mathrm{SE}=.003$, 
$\mathrm{z}=1.58, p=.11)$, but through party affiliation $(\beta=.298, \mathrm{SE}=.036, \mathrm{z}=8.39, p<.001)$ and education $(\beta=.020, \mathrm{SE}=.006, z=3.68, p<.001)$ were significant.

\section{Individual Mediators}

Resentment. The effect of rural versus urban residence on resentment toward government employees $(\beta=.042, \mathrm{SE}=.012, z=3.53, p<.001)$ was significant (Figure 3$)$. When examining the partial effects of the predictor variable and the mediator on the dependent variable, ruralurban residence $(\beta=.378, \mathrm{SE}=.032, z=11.87, p<.001)$ and resentment $(\beta=.529, \mathrm{SE}=.047, z$ $=11.31, p<.001$ ) were statistically significant (Figure 3 ). The indirect effect of rural residence on voting behavior through feelings of resentment $(\beta=.022, \mathrm{SE}=.007, \mathrm{z}=3.37, p=.001)$ was significant.

Party Affiliation. The effect of rural versus urban residence on party affiliation $(\beta=.344$, $\mathrm{SE}=.037, z=9.32, p<.001$ ) was significant (Figure 3). When examining the partial effects of the predictor variable and the mediator on the dependent variable, rural residence $(\beta=.113, \mathrm{SE}=$ $.026, z=4.32, p<.001)$ and party affiliation $(\beta=.937, \mathrm{SE}=0.008, z=122.11, p<.001)$ were statistically significant (Figure 3). The indirect effect of rural residence on voting behavior through party affiliation $(\beta=.322, \mathrm{SE}=.035, \mathrm{z}=9.30, p<.001)$ was significant.

Education. The effect of rural versus urban residence on education $(\beta=-.386, \mathrm{SE}=.038$, $z=-10.28, p<.001)$ was significant. When examining the partial effects of the predictor variable and the mediator on the dependent variable, rural residence $(\beta=.374, \mathrm{SE}=.031, z=11.96, p<$ $.001)$ and education $(\beta=-0.132, \mathrm{SE}=.014, z=-9.42, p<.001)$ were statistically significant

(Figure 3). The indirect effect of rural residence on voting behavior through education $(\beta=.051$, $\mathrm{SE}=.007, z=6.95, p<.001)$ was significant.

\section{Interior versus Elite Coastal State}


The second demographic characteristic of interest was living in an interior versus elite coastal state. We tested mediation analyses for the interior-elite demographic variable in both the MTurk/Facebook and UAS samples.

\section{Parallel Mediators (UAS Sample)}

The effect of living in an interior versus elite coastal state on resentment toward government employees $(\beta=.041, \mathrm{SE}=.027, z=1.51, p=.130)$ was not significant, but on party affiliation $(\beta=.343, \mathrm{SE}=.072, z=4.77, p<.001)$ and education $(\beta=-.473, \mathrm{SE}=.089, z=-5.34$, $p<.001$ ) was significant (Figure 4). When examining the partial effects of the predictor variable and the mediator on the dependent variable, interior state $(\beta=.103, \mathrm{SE}=.045, z=2.31, p=$ $.021)$, resentment $(\beta=.153, \mathrm{SE}=.038, z=3.97, p<.001)$, party affiliation $(\beta=.917, \mathrm{SE}=$ $0.009, z=97.60, p<.001)$, and education $(\beta=-.058, \mathrm{SE}=.013, z=-4.44, p<.001)$ were statistically significant (Figure 4). The indirect effect of living in an interior state on voting behavior through feelings of resentment $(\beta=.006, \mathrm{SE}=.004, \mathrm{z}=1.41, p=.16)$ was not significant, but the indirect effects of party affiliation $(\beta=.315, \mathrm{SE}=.066, \mathrm{z}=4.76, p<.001)$ and education $(\beta=.028, \mathrm{SE}=.008, z=3.40, p=.001)$ were significant.

\section{Parallel Mediators (MTurk/Facebook Sample)}

The effect of living in an interior versus elite coastal state on resentment toward government employees $(\beta=.012, \mathrm{SE}=.036, z=.34, p=.73)$ and education $(\beta=-.116, \mathrm{SE}=$ $.074, z=-1.57, p=.12)$ was not significant, but on party affiliation $(\beta=.226, \mathrm{SE}=.087, z=$ $2.60, p=.009$ ) was significant (Figure S5). When examining the partial effects of the predictor variable and the mediator on the dependent variable, interior state $(\beta=-.046, \mathrm{SE}=.043, z=-$ $1.08, p=.28)$ was not significant, but resentment $(\beta=.136, \mathrm{SE}=.041, z=3.29, p=.001)$, party affiliation $(\beta=.956, \mathrm{SE}=0.009, z=107.46, p<.001)$, and education $(\beta=-.057, \mathrm{SE}=.020, z=-$ 
$2.79, p=.005$ ) were statistically significant (Figure S5). The indirect effect of living in an interior state on voting behavior through feelings of resentment $(\beta=.002, \mathrm{SE}=.005, \mathrm{z}=.34, p=$ .734) and education $(\beta=0.007, \mathrm{SE}=.005, z=1.37, p=.170)$ were not significant, but the indirect effect of party affiliation $(\beta=.216, \mathrm{SE}=.083, \mathrm{z}=2.604, p=.009)$ was significant. Individual Mediators (UAS Sample)

Resentment. The effect of living in an interior versus elite coastal state on resentment toward government employees $(\beta=.034, \mathrm{SE}=.022, z=1.57, p=.12)$ was not significant (Figure 3). When examining the partial effects of the predictor variable and the mediator on the dependent variable, interior state $(\beta=.360, \mathrm{SE}=.058, z=6.25, p<.001)$ and resentment $(\beta=$ $.547, \mathrm{SE}=.045, z=12.26, p<.001$ ) were statistically significant (Figure 3 ). The indirect effect of living in an interior state on voting behavior through feelings of resentment $(\beta=.019, \mathrm{SE}=$ $.012, \mathrm{z}=1.55, p=.12)$ was not significant.

Party Affiliation. The effect of living in an interior versus elite coastal state on party affiliation $(\beta=.323, \mathrm{SE}=.068, z=4.72, p<.001)$ was significant (Figure 3$)$. When examining the partial effects of the predictor variable and the mediator on the dependent variable, interior state $(\beta=.139, \mathrm{SE}=.043, z=3.26, p=.001)$ and party affiliation $(\beta=.939, \mathrm{SE}=.007, z=$ $127.14, p<.001$ ) were statistically significant (Figure 3). The indirect effect of living in an interior state on voting behavior through party affiliation $(\beta=.303, \mathrm{SE}=.064, \mathrm{z}=4.72, p<.001)$ was significant.

Education. The effect of living in an interior versus elite coastal state on education $(\beta=-$ $.423, \mathrm{SE}=.070, z=-6.05, p<.001$ ) was significant (Figure 3). When examining the partial effects of the predictor variable and the mediator on the dependent variable, interior state $(\beta=$ $.312, \mathrm{SE}=.056, z=5.57, p<.001)$ and education $(\beta=-.151, \mathrm{SE}=.013, z=-11.24, p<.001)$ 
were statistically significant (Figure 3). The indirect effect of living in an interior state on voting behavior through education $(\beta=.064, \mathrm{SE}=.012, z=5.32, p<.001)$ was significant.

\section{Individual Mediators (MTurk/Facebook Sample)}

Resentment. The effect of living in an interior versus elite coastal state on resentment toward government employees $(\beta=.003, \mathrm{SE}=.029, z=.100, p=.920)$ was not significant (Figure S4). When examining the partial effects of the predictor variable and the mediator on the dependent variable, interior state $(\beta=.181, \mathrm{SE}=.070, z=2.59, p=.010)$ and resentment $(\beta=$ $.525, \mathrm{SE}=.053, z=9.87, p<.001)$ were statistically significant (Figure S4). The indirect effect of living in an interior state on voting behavior through feelings of resentment $(\beta=.002, \mathrm{SE}=$ $.015, \mathrm{z}=.100, p=.920)$ was not significant.

Party Affiliation. The effect of living in an interior versus elite coastal state on party affiliation $(\beta=.215, \mathrm{SE}=.086, z=2.50, p=.012)$ was significant (Figure S4). When examining the partial effects of the predictor variable and the mediator on the dependent variable, interior state $(\beta=-.043, \mathrm{SE}=.043, z=-.98, p=.33)$ was not significant, but party affiliation $(\beta=.979$, $\mathrm{SE}=.005, z=194.27, p<.001)$ was statistically significant (Figure S4). The indirect effect of living in an interior state on voting behavior through party affiliation $(\beta=.211, \mathrm{SE}=.084, \mathrm{z}=$ $2.50, p=.012)$ was significant.

Education. The effect of living in an interior versus elite coastal state on education $(\beta=-$ $.124, \mathrm{SE}=.062, z=-2.01, p=.045$ ) was significant (Figure S4). When examining the partial effects of the predictor variable and the mediator on the dependent variable, interior state $(\beta=$ $.149, \mathrm{SE}=.071, z=2.09, p=.036)$ and education $(\beta=-.195, \mathrm{SE}=.028, z=-6.87, p<.001)$ were statistically significant (Figure S4). The indirect effect of living in an interior state on voting behavior through and education $(\beta=.024, \mathrm{SE}=.013, z=1.93, p=.054)$ was marginal. 


\section{Supplementary Text S3}

\section{Analysis of state of Wisconsin for UAS and MTurk/Facebook Samples.}

UAS Sample. Based on the politics of resentment account (Cramer 2016a, 2016b), one might expect that living in a rural part of Wisconsin would be especially likely to predict resentment. A regression was conducted entering rural versus urban status, living in Wisconsin versus other states, and their interaction as predictors of resentment. Results indicated that while living in a rural area predicted rural resentment $(B=.079, S E=.036, t=2.21, p=.027)$, living in Wisconsin did not predict resentment $(B=.036, S E=.052, t=.68, p=.50)$, nor did the interaction between living in Wisconsin and living in a rural area $(B=.082, S E=.071, t=1.15$, $p=.25)$.

We also examined whether living in Wisconsin and voting for Trump predicted greater resentment than living in other states and voting for Trump. A regression was conducted entering voting for Trump versus Clinton, living in Wisconsin versus other states, and their interaction as predictors of resentment. Living in Wisconsin did not predict greater resentment $(B=.06, S E=$ $.05, t=1.25, p=.21)$, voting for Trump did predict greater resentment $(B=.18, S E=.05, t=$ $3.66, p<.001)$, but the interaction of living in Wisconsin and voting for Trump was not significant $(B=-.018, S E=.098, t=-.19, p=.85)$.

MTurk/Facebook Sample. For the MTurk/Facebook sample, we oversampled from Wisconsin slightly $(N=219)$ to test whether living in Wisconsin (coded as 1$)$ would lead to differences in resentment and admiration, relative to the rest of the United States (coded as 0). First, a repeated measures ANOVA comparing Wisconsin to the rest of the United States on Resentment and Admiration revealed no significant differences in Admiration (WI: $M=1.89, S D$ $=.74$, Median $=2.0$, Min $=0$, Max $=3$, Rest of US: $M=1.74, S D=.74$, Median $=1.83$, Min $=0$, 
Max =3) or Resentment (WI: $M=.38, S D=.53$, Median $=.167$, Min $=0$, Max $=2.56$; rest of the US: $M=.34, S D=.53$, Median $=0, \operatorname{Min}=0, \operatorname{Max}=3), F(1,2230)=2.27, p=.13$.

We also examined whether living in Wisconsin and voting for Trump predicted greater resentment. A regression was conducted entering voting for Trump versus Clinton, living in Wisconsin versus other states, and their interaction as predictors of resentment. In this model, living in Wisconsin did predict greater resentment than the rest of the United States $(B=.12, S E$ $=.051, t=2.25, p=.025)$, voting for Trump also predicted greater resentment $(B=.33, S E=$ $.051, t=6.37, p<.001)$, but the interaction of living in Wisconsin and voting for Trump did not predict resentment $(B=.099, S E=.103, t=.96, p=.34)$. These analyses, however, should be taken with a grain of salt given the sample imbalance between living in Wisconsin versus the rest of the United States. 


\section{Supplementary References}

Berinsky, Adam J., Gregory A. Huber, and Gabriel S. Lenz. 2012. "Evaluating online labor markets for experimental research: Amazon. com's Mechanical Turk." Political Analysis 20 (3): 351-368.

Chang, Linchiat, and Jon A. Krosnick. 2009. "National surveys via RDD telephone interviewing versus the Internet: Comparing sample representativeness and response quality." Public Opinion Quarterly 73 (4): 641-678.

Huff, Connor, and Dustin Tingley. 2015. ““Who are these people?” Evaluating the demographic characteristics and political preferences of MTurk survey respondents." Research \& Politics 2 (3): 2053168015604648.

Mayer, John D., and Yvonne N. Gaschke. 1988. "The experience and meta-experience of mood." Journal of Personality and Social Psychology 55 (1): 102.

Yeager, David S., Jon A. Krosnick, LinChiat Chang, Harold S. Javitz, Matthew S. Levendusky, Alberto Simpser, and Rui Wang. 2011. "Comparing the accuracy of RDD telephone surveys and internet surveys conducted with probability and non-probability samples." Public Opinion Quarterly 75 (4): 709-747. 
Table S1.

Demographic Information for MTurk/Facebook and UAS Samples.

\begin{tabular}{|c|c|c|c|}
\hline Item & Category & $\%(\mathbf{N})$ & $\%(\mathrm{~N})$ \\
\hline \multirow[t]{3}{*}{ Gender } & Female & $49.0(1107)$ & $56.2(2148)$ \\
\hline & Male & $51.0(1152)$ & $43.8(1672)$ \\
\hline & Total & 2259 & 3820 \\
\hline \multirow[t]{9}{*}{ Political Party } & Democrat & $39.8(901)$ & $34.1(1179)$ \\
\hline & Republican & $18.4(416)$ & $33.7(1168)$ \\
\hline & Independent & $20.0(452)$ & $19.6(677)$ \\
\hline & $\begin{array}{l}\text { Registered but } \\
\text { No Party } \\
\text { Affiliation }\end{array}$ & $16.6(377)$ & $11.7(406)$ \\
\hline & Green & $\mathrm{n} / \mathrm{a}$ & $.2(8)$ \\
\hline & Libertarian & $\mathrm{n} / \mathrm{a}$ & $.3(11)$ \\
\hline & Other Party & $1.2(27)$ & $.2(9)$ \\
\hline & Not Registered & $4.0(92)$ & $\mathrm{n} / \mathrm{a}$ \\
\hline & Total & 2265 & 3458 \\
\hline \multirow[t]{8}{*}{ Education } & $<$ High School & $.5(12)$ & $5.0(192)$ \\
\hline & $\begin{array}{l}\text { High School } \\
\text { Degree }\end{array}$ & $26.2(594)$ & $19.5(745)$ \\
\hline & Some College & $\mathrm{n} / \mathrm{a}$ & $22.8(869)$ \\
\hline & $\begin{array}{l}\text { 2-Yr. College } \\
\text { Degree }\end{array}$ & $17.1(388)$ & $14.8(566)$ \\
\hline & $\begin{array}{l}\text { 4-Yr. College } \\
\text { Degree }\end{array}$ & $40.9(928)$ & $21.9(838)$ \\
\hline & Master's Degree & $11.6(262)$ & $12.1(460)$ \\
\hline & $\begin{array}{l}\text { PhD or Prof. } \\
\text { Degree }\end{array}$ & $3.7(83)$ & $3.9(149)$ \\
\hline & Total & 2267 & 3819 \\
\hline \multirow[t]{7}{*}{ Race/Ethnicity } & $\begin{array}{l}\text { Asian/Pacific } \\
\text { Islander }\end{array}$ & $8.2(176)$ & $1.8(68)$ \\
\hline & $\begin{array}{l}\text { Black/African } \\
\text { Am. }\end{array}$ & $7.4(159)$ & $8.7(333)$ \\
\hline & Native American & $1.3(27)$ & $.8(30)$ \\
\hline & White/Caucasian & $81.6(1758)$ & $84.1(3207)$ \\
\hline & Other & $1.5(33)$ & $4.6(174)$ \\
\hline & Total & 2153 & 3812 \\
\hline & Hispanic/Latino & $5.0(114)$ & $6.8(260)$ \\
\hline
\end{tabular}




\begin{tabular}{|c|c|c|c|}
\hline & Non & $95(2153)$ & $93.2(3559)$ \\
\hline & Hispanic/Latino & & \\
\hline & Total & 2267 & 3819 \\
\hline Age & $18-24$ & $14.7(334)$ & $3.1(120)$ \\
\hline & $25-34$ & $43.1(979)$ & $13.4(510)$ \\
\hline & $35-44$ & $20.9(474)$ & $18.6(710)$ \\
\hline & $45-54$ & $10.7(242)$ & $20.0(762)$ \\
\hline & $55-59$ & $4.9(111)$ & $12.4(474)$ \\
\hline & $60-64$ & $3.0(68)$ & $11.3(432)$ \\
\hline & $65-74$ & $2.5(57)$ & $15.6(593)$ \\
\hline & $75-84$ & $.2(5)$ & $4.8(184)$ \\
\hline & 85 or older & $.0(1)$ & $.8(32)$ \\
\hline & Total & 2271 & 3817 \\
\hline Voter Choice & Clinton & $48.8(1108)$ & $42.5(1449)$ \\
\hline & Trump & $23.8(539)$ & $51.7(1762)$ \\
\hline & Johnson & $6.2(141)$ & $2.4(81)$ \\
\hline & Stein & $3.6(81)$ & $.8(28)$ \\
\hline & Other & $2.3(52)$ & $2.2(76)$ \\
\hline & Did Not Vote & $15.3(346)$ & $.4(12)$ \\
\hline & Total & 2267 & 3408 \\
\hline State & Alabama & $1.5(35)$ & $1.8(70)$ \\
\hline & Alaska & $.3(6)$ & $.1(5)$ \\
\hline & Arizona & $2.0(45)$ & $2.0(77)$ \\
\hline & Arkansas & $.6(14)$ & $1.9(71)$ \\
\hline & California* & $9.4(213)$ & $6.4(245)$ \\
\hline & Colorado & $1.7(39)$ & $1.4(54)$ \\
\hline & Connecticut* & $1.2(27)$ & $.9(36)$ \\
\hline & D.C.* & $.4(9)$ & $.2(8)$ \\
\hline & Delaware* & $.3(7)$ & $.1(5)$ \\
\hline & Florida & $6.9(158)$ & $4.9(189)$ \\
\hline & Georgia & $2.4(54)$ & 3.1 (119) \\
\hline & Hawaii & $.3(7)$ & $.2(6)$ \\
\hline & Idaho & $.4(10)$ & $.7(28)$ \\
\hline & Illinois & $4.2(96)$ & $4.5(172)$ \\
\hline & Indiana & $2.0(45)$ & 2.7 (104) \\
\hline & Iowa & $.4(9)$ & $2.0(77)$ \\
\hline & Kansas & $.5(12)$ & $2.3(88)$ \\
\hline & Kentucky & $.9(21)$ & $2.1(79)$ \\
\hline & Louisiana & $1.3(30)$ & $1.0(37)$ \\
\hline & Maine & $.4(10)$ & $.8(31)$ \\
\hline & Maryland* & $1.3(29)$ & $.8(32)$ \\
\hline & Massachusetts* & $2.1(48)$ & $1.2(44)$ \\
\hline & Michigan & $3.1(71)$ & 4.3 (164) \\
\hline
\end{tabular}




\begin{tabular}{|c|c|c|}
\hline Minnesota & $1.5(35)$ & $2.0(75)$ \\
\hline Mississippi & $1.0(23)$ & $1.3(50)$ \\
\hline Missouri & $1.8(40)$ & $2.6(101)$ \\
\hline Montana & $.1(3)$ & $.3(10)$ \\
\hline Nebraska & $.5(11)$ & $.9(35)$ \\
\hline Nevada & $1.1(25)$ & $.5(18)$ \\
\hline New Hampshire & $.3(7)$ & $.3(12)$ \\
\hline New Jersey* & $2.2(49)$ & $1.5(59)$ \\
\hline New Mexico & $.7(16)$ & $.6(22)$ \\
\hline New York* & $6.0(137)$ & $4.0(153)$ \\
\hline North Carolina & $3.7(83)$ & $3.8(147)$ \\
\hline North Dakota & $.2(4)$ & $.6(22)$ \\
\hline Ohio & $2.9(65)$ & $6.0(229)$ \\
\hline Oklahoma & $.9(21)$ & $.7(28)$ \\
\hline Oregon* & $2.2(50)$ & $1.2(45)$ \\
\hline Pennsylvania & $5.2(118)$ & $7.3(277)$ \\
\hline Rhode Island* & $.7(15)$ & $.1(2)$ \\
\hline South Carolina & $1.3(30)$ & $1.2(47)$ \\
\hline South Dakota & $.1(2)$ & $1.0(38)$ \\
\hline Tennessee & $1.5(34)$ & $2.1(80)$ \\
\hline Texas & $6.0(136)$ & $5.9(225)$ \\
\hline Utah & $.7(15)$ & $.5(17)$ \\
\hline Vermont* & $.2(4)$ & $.2(7)$ \\
\hline Virginia & $2.1(47)$ & $2.7(105)$ \\
\hline Washington* & $2.5(57)$ & $1.7(66)$ \\
\hline West Virginia & $.7(15)$ & $2.3(87)$ \\
\hline Wisconsin & $9.6(219)$ & $3.1(117)$ \\
\hline Wyoming & $.2(4)$ & $.1(4)$ \\
\hline $\begin{array}{l}\text { United States (not } \\
\text { specified) }\end{array}$ & $.5(12)$ & $.1(1)$ \\
\hline Total & 2272 & 3820 \\
\hline
\end{tabular}

Note: * Indicates inclusion in the "elite coastal" state variable 


\section{Table S2.}

UAS sample correlations among nine emotions felt toward state employees, collapsed across state employee category.

Pride Disgust Admiration Resentment Jealousy Anger $\underset{\substack{\text { Grateful } \\ \text { ness }}}{\text { Fear }}$ Shame

\begin{tabular}{|c|c|c|c|c|c|c|c|c|}
\hline Pride & $1.085^{* *}$ & $.728 * *$ & $-.135^{* *}$ & $.078 * *$ & $-.225^{* *}$ & $.653 * *$ & $-.051 *$ & $-.152 * *$ \\
\hline Disgust & 1 & $.046 * *$ & $.467 * *$ & $.324 * *$ & $.429 * *$ & $.048 * *$ & $.393 * *$ & $.388 * *$ \\
\hline Admiration & & 1 & $-.150 * *$ & $.093 * *$ & $-.228 * *$ & $.717 * *$ & $-.064 * *$ & $-.162 * *$ \\
\hline Resentment & & & 1 & $.532 * *$ & $.701 * *$ & $-.140 * *$ & $.587 * *$ & $.643^{* *}$ \\
\hline Jealousy & & & & 1 & $.489 * *$ & $.144 * *$ & $.584 * *$ & $.505^{* *}$ \\
\hline Anger & & & & & 1 & $-.190 * *$ & $.627 * *$ & $.743 * *$ \\
\hline Gratefulness & & & & & & 1 & $-.001 * *$ & $-.120 * *$ \\
\hline Fear & & & & & & & 1 & $.686^{* *}$ \\
\hline Shame & & & & & & & & 1 \\
\hline
\end{tabular}


Table S3.

Correlations among predictor variables.

MTurk/Facebook

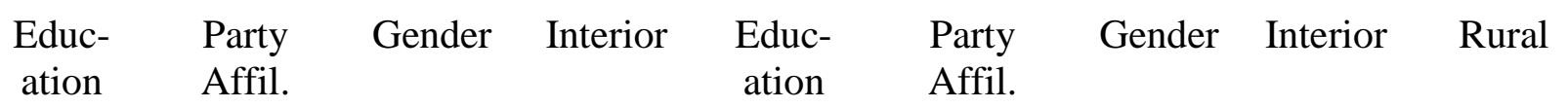


Table S4.

UAS sample multiple regression results examining if social identities predict resentment.

Coefficients are unstandardized.

\begin{tabular}{|c|c|c|c|c|c|}
\hline Model Number & Variables & $\beta$ & S.E. & $t$ & $p$ \\
\hline \multirow[t]{15}{*}{1} & Rural (R) & -.002 & .014 & -.149 & .882 \\
\hline & Education (E) & -.050 & .007 & -7.305 & .000 \\
\hline & Gender $(\mathrm{G})$ & .027 & .022 & 1.276 & .202 \\
\hline & Party Affil. (P) & .094 & .022 & 4.346 & .000 \\
\hline & $\mathrm{P} \times \mathrm{R}$ & -.022 & .028 & -.758 & .449 \\
\hline & $\mathrm{P} \times \mathrm{E}$ & .019 & .014 & 1.364 & .173 \\
\hline & $G \times R$ & -.039 & .028 & -1.385 & .166 \\
\hline & $\mathrm{R} \times \mathrm{E}$ & -.001 & .009 & -.152 & .880 \\
\hline & $P \times G$ & .062 & .043 & 1.440 & .150 \\
\hline & E x G & -.021 & .014 & -1.512 & .131 \\
\hline & $R \times E \times G$ & .006 & .018 & .351 & .726 \\
\hline & $R \times G \times P$ & -.045 & .057 & -.787 & .431 \\
\hline & $R \times E \times P$ & -.026 & .018 & -1.440 & .150 \\
\hline & E x G x P & -.011 & .027 & -.387 & .699 \\
\hline & $R \times G \times E \times P$ & -.027 & .036 & -.752 & .452 \\
\hline \multirow[t]{15}{*}{2} & Interior (I) & -.030 & .027 & -1.094 & .274 \\
\hline & Education (E) & -.053 & .009 & -6.087 & .000 \\
\hline & Gender $(\mathrm{G})$ & .014 & .027 & .529 & .597 \\
\hline & Party Affil. (P) & .150 & .027 & 5.484 & .000 \\
\hline & P x I & -.164 & .055 & -3.004 & .003 \\
\hline & $P \times E$ & .025 & .018 & 1.441 & .150 \\
\hline & $\mathrm{G} \times \mathrm{I}$ & .016 & .055 & .301 & .764 \\
\hline & I x E & .011 & .018 & .620 & .535 \\
\hline & $P \times G$ & .019 & .055 & .354 & .723 \\
\hline & $\mathrm{E} \times \mathrm{G}$ & -.024 & .018 & -1.357 & .175 \\
\hline & I x Ex G & .016 & .035 & .460 & .645 \\
\hline & $I \times G \times P$ & .122 & .109 & 1.114 & .265 \\
\hline & I x Ex P & -.043 & .035 & -1.223 & .221 \\
\hline & $E \times G \times P$ & -.006 & .035 & -.161 & .872 \\
\hline & I x G x Ex P & .013 & .070 & .184 & .854 \\
\hline
\end{tabular}




\section{Table S5}

Comparison of unweighted and weighted data in the UAS sample. Numbers reflect descriptive statistics.

\begin{tabular}{|c|c|c|c|c|c|c|c|c|c|c|c|}
\hline \multirow[t]{3}{*}{ Characteristic } & \multirow[t]{3}{*}{ Level } & \multicolumn{4}{|c|}{ Admiration } & \multicolumn{4}{|c|}{ Resentment } & \multicolumn{2}{|c|}{ Sample Percent } \\
\hline & & \multicolumn{2}{|c|}{ Unweighted } & \multicolumn{2}{|c|}{ Weighted } & \multicolumn{2}{|c|}{ Unweighted } & \multicolumn{2}{|c|}{ Weighted } & \multirow{2}{*}{$\begin{array}{c}\text { Unweighted } \\
\%\end{array}$} & \multirow{2}{*}{$\begin{array}{c}\text { Weighted } \\
\%\end{array}$} \\
\hline & & Mean & $S D$ & Mean & $S D$ & Mean & $S D$ & Mean & $S D$ & & \\
\hline & $<H S$ & 1.58 & .63 & 1.59 & .62 & .96 & .48 & .93 & .47 & 5.0 & 8.4 \\
\hline & HS Degree & 1.72 & .62 & 1.71 & .61 & .91 & .51 & .91 & .53 & 19.5 & 32.4 \\
\hline & $\begin{array}{l}\text { Some } \\
\text { College }\end{array}$ & 1.79 & .61 & 1.81 & .61 & .81 & .47 & .84 & .56 & 22.8 & 18.0 \\
\hline & $\begin{array}{l}2-Y r \\
\text { College }\end{array}$ & 1.77 & .59 & 1.72 & .61 & .80 & .45 & .82 & .44 & 14.8 & 10.5 \\
\hline \multirow[t]{4}{*}{ Education } & $\begin{array}{l}\text { Degree } \\
4-Y r \\
\text { College } \\
\text { Degree }\end{array}$ & 1.79 & .58 & 1.83 & .59 & .71 & .42 & .68 & .40 & 21.9 & 17.8 \\
\hline & $\begin{array}{l}\text { Master's } \\
\text { Degree }\end{array}$ & 1.90 & .56 & 1.87 & .57 & .66 & .42 & .66 & .44 & 12.0 & 9.7 \\
\hline & $\begin{array}{l}\text { PhD/Prof. } \\
\text { Degree }\end{array}$ & 1.78 & .60 & 1.67 & .61 & .63 & .45 & .63 & .44 & 3.9 & 3.2 \\
\hline & Urban & 1.80 & .57 & 1.76 & .59 & .74 & .48 & .77 & .48 & 22.4 & 36.7 \\
\hline \multirow{3}{*}{ Rural-Urban } & Mixed & 1.79 & .60 & 1.75 & .62 & .78 & .46 & .83 & .48 & 44.5 & 54.3 \\
\hline & Rural & 1.74 & .62 & 1.73 & .62 & .82 & .45 & .84 & .46 & 33.1 & 8.9 \\
\hline & Elite Coast & 1.73 & .60 & 1.71 & .61 & .76 & .47 & .78 & .48 & 18.4 & 24.7 \\
\hline \multirow[t]{2}{*}{ Interior } & Interior & 1.79 & .60 & 1.77 & .60 & .79 & .46 & .82 & .48 & 81.6 & 75.3 \\
\hline & Democrat & 1.90 & .56 & 1.91 & .56 & .72 & .46 & .75 & .49 & 50.2 & 55.9 \\
\hline \multirow[t]{2}{*}{ Party Affil. } & Republican & 1.69 & .63 & 1.63 & .86 & .83 & .48 & .86 & .49 & 49.8 & 44.1 \\
\hline & Female & 1.85 & .58 & 1.84 & .60 & .77 & .45 & .78 & .46 & 56.2 & 51.7 \\
\hline \multirow[t]{2}{*}{ Gender } & Male & 1.68 & .61 & 1.67 & .60 & .80 & .48 & .85 & .49 & 43.8 & 48.3 \\
\hline & Clinton & 1.92 & .53 & 1.91 & .55 & .67 & .43 & .70 & .45 & 45.1 & 51.4 \\
\hline Vote & Trump & 1.68 & .63 & 1.63 & .62 & .86 & .48 & .90 & .50 & 54.9 & 48.6 \\
\hline
\end{tabular}


Table S6

Comparison of mixed-model analyses examining the relationship between admiration and

resentment of government employees using unweighted and weighted data in the UAS sample.

\begin{tabular}{|c|c|}
\hline \multicolumn{2}{|c|}{ Admiration is Higher than Resentment at the Aggregate } \\
\hline Unweighted & Weighted \\
\hline Admiration: $M=1.77, S D=.60$ & Admiration: $M=1.75, S D=.60$ \\
\hline Resentment: $M=.78, S D=.46$ & Resentment: $M=.81, S D=.47$ \\
\hline Paired samples t-test: $t(3423)=73.53, p<.001$ & Paired samples t-test: $t(3325)=68.46, p<.001$ \\
\hline \multicolumn{2}{|c|}{ Admiration is Higher than Resentment Across all Demographic Categories of Interest } \\
\hline Unweighted & Weighted \\
\hline $\begin{array}{l}\text { Rural-Urban Divide } \\
\text { Feeling effect: } F(1,3394)=5046.91, p<.001 \\
\text { Rural-Urban effect: } F(2,3394)=.53, p=.59 \\
\text { Interaction effect: } F(2,3394)=8.40, p<.001 \\
\text { Simple effects: } \\
\text { Rural: } F(1,3394)=1554.69, p<.001 \\
\text { Mixed: } F(1,3394)=2461.85, p<.001 \\
\text { Urban: } F(1,3394)=1383.93, p<.001\end{array}$ & $\begin{array}{l}\text { Rural-Urban Divide } \\
\text { Feeling effect: } F(1,2906)=205.07, p<.001 \\
\text { Rural-Urban effect: } F(2,2906)=1.71, p=.18 \\
\text { Interaction effect: } F(2,2906)=6.88, p<.001 \\
\text { Simple effects: } \\
\text { Rural: } F(1,2906)=7.86, p=.005 \\
\text { Mixed: } F(1,2906)=2269.57, p<.001 \\
\text { Urban: } F(1,2906)=1844.09, p<.001\end{array}$ \\
\hline $\begin{array}{l}\text { Interior } \\
\text { Feeling effect: } \mathrm{F}(1,3421)=3204.49, p<.001 \\
\text { Interior effect: } \mathrm{f}(1,3421)=7.76, p=.005 \\
\text { Interaction Effect: } F(1,3421)=.42, p=.52 \\
\text { Simple effects: } \\
\text { Interior: } F(1,3421)=4446.03, p<.001 \\
\text { Coastal: } F(1,3421)=959.80, p<.001\end{array}$ & $\begin{array}{l}\text { Interior } \\
\text { Feeling effect: } F(1,2938)=3304.73, p<.001 \\
\text { Interior effect: } F(1,2938)=13.62, p<.001 \\
\text { Interaction Effect: } F(1,2938)=.007, p=.93 \\
\text { Simple effects: } \\
\text { Interior: } F(1,2938)=3007.40, p<.001 \\
\text { Coastal: } F(1,2938)=1137.08, p<.001\end{array}$ \\
\hline $\begin{array}{l}\text { Education } \\
\text { Feeling effect: } F(1,3416)=3589.83, p<.001 \\
\text { Education effect: } F(6,3416)=3.39, p=.002 \\
\text { Interaction Effect: } F(6,3416)=21.96, p<.001 \\
\text { Simple effects: } \\
\text { Less than high school: } F(1,3416)=97.64, p<.001 \\
\text { High school: } F(1,3416)=720.04, p<.001 \\
\text { Some college: } F(1,3416)=1199.98, p<.001 \\
\text { 2-year college: } F(1,3416)=785.42, p<.001 \\
\text { 4-year college: } F(1,3416)=1507.87, p<.001 \\
\text { Master's: } F(1,3416)=1093.14, p<.001 \\
\text { Doctorate: } F(1,3416)=331.41, p<.001\end{array}$ & $\begin{array}{l}\text { Education } \\
\text { Feeling effect: } F(1,2932)=2898.01, p<.001 \\
\text { Education effect: } F(6,2932)=5.32, p<.001 \\
\text { Interaction Effect: } F(6,2932)=24.51, p<.001 \\
\text { Simple effects: } \\
\text { Less than high school: } F(1,2932)=159.53, p<.001 \\
\text { High school: } F(1,2932)=1094.34, p<.001 \\
\text { Some college: } F(1,2932)=801.65, p<.001 \\
\text { 2-year college: } F(1,2932)=335.71, p<.001 \\
\text { 4-year college: } F(1,2932)=1224.11, p<.001 \\
\text { Master's: } F(1,2932)=682.27, p<.001 \\
\text { Doctorate: } F(1,2932)=191.42, p<.001 \\
\end{array}$ \\
\hline $\begin{array}{l}\text { Party Affiliation } \\
\text { Feeling effect: } F(1,2115)=3539.36, p<.001 \\
\text { Party effect: } F(1,2115)=12.64, p<.001 \\
\text { Interaction effect: } F(1,2115)=90.06, p<.001 \\
\text { Simple effects: } \\
\text { Republican: } F(1,2115)=1239.00, p<.001 \\
\text { Democrat: } F(1,2115)=2400.85, p<.001\end{array}$ & $\begin{array}{l}\text { Party Affiliation } \\
\text { Feeling effect: } F(1,1811)=2620.48, p<.001 \\
\text { Party effect: } \mathrm{F}(1,1811)=33.58, p<.001 \\
\text { Interaction effect: } F(1,1811)=112.69, \mathrm{p}<.001 \\
\text { Simple effects: } \\
\text { Republican: } F(1,1811)=727.30, p<.001 \\
\text { Democrat: } F(1,1811)=2200.01, p<.001\end{array}$ \\
\hline $\begin{array}{l}\text { Gender } \\
\text { Feeling effect: } F(1,3422)=5273.83, p<.001 \\
\text { Gender effect: } F(1,3422)=35.51, p<.001 \\
\text { Interaction effect: } F(1,3422)=55.01, p<.001 \\
\text { Simple effects: } \\
\text { Male: } F(1,3422)=1891, p<.001 \\
\text { Female: } F(1,3422)=3655, p<.001\end{array}$ & $\begin{array}{l}\text { Gender } \\
\text { Feeling effect: } F(1,2939)=4216.63, p<.001 \\
\text { Gender effect: } F(1,2939)=13.58, p<.001 \\
\text { Interaction effect: } F(1,2939)=80.53, p<.001 \\
\text { Simple effects: } \\
\text { Male: } F(1,2939)=1516.85, p<.001 \\
\text { Female: } F(1,2939)=2822.48, p<.001\end{array}$ \\
\hline
\end{tabular}


Table S7.

Indirect effects of rural and interior living through feelings of resentment, party affiliation, and education (models 1-3 contain individual mediators, model 4 contains parallel mediators), on the likelihood of voting for Trump over Clinton. Coefficients are unstandardized. Here we abbreviate the MTurk/Facebook sample as "MTurk".

\begin{tabular}{|c|c|c|c|c|c|c|}
\hline $\begin{array}{l}\text { Model } \\
\mathrm{Nr}\end{array}$ & Sample & $\begin{array}{l}\text { Distant } \\
\text { Cause } \\
(\mathrm{X})\end{array}$ & $\begin{array}{l}\text { Proximal } \\
\text { Cause } \\
\text { (M) }\end{array}$ & $\begin{array}{c}\text { Indirect } \\
\text { Effect } \\
(\mathrm{ab})\end{array}$ & $\begin{array}{l}\text { Total } \\
\text { Effect } \\
\text { (c) }\end{array}$ & $\begin{array}{l}\text { Per- } \\
\text { cent } \\
(\mathrm{ab} / \mathrm{c})\end{array}$ \\
\hline \multicolumn{7}{|c|}{ Individual Mediators } \\
\hline 1 & MTurk & Interior & Resentment & $.002[.015]$ & $.182 *[.072]$ & $1.10 \%$ \\
\hline 2 & MTurk & Interior & Party Affil. & $.211 *[.084]$ & $.168 *[.086]$ & $125.60 \%$ \\
\hline 3 & MTurk & Interior & Education & $.024^{\dagger}[.013]$ & $.173[.072]$ & $13.87 \%$ \\
\hline \multicolumn{7}{|c|}{ Parallel Mediators } \\
\hline 4 & MTurk & Interior & Resentment & $.002[.005]$ & $.178 *[.086]$ & $1.12 \%$ \\
\hline 4 & MTurk & Interior & Party Affil. & $.216 * *[.083]$ & $.178 *[.086]$ & $121.35 \%$ \\
\hline 4 & MTurk & Interior & Education & $.007[.005]$ & $.178 *[.086]$ & $3.93 \%$ \\
\hline
\end{tabular}


Table S8.

MTurk/Facebook sample multiple regression results examining if social identities predict resentment. Coefficients are unstandardized.

$\begin{array}{lcccc} & B & S . E & t & p \\ \text { Interior (I) } & -.064 & .037 & -1.73 & .084 \\ \text { Education (E) } & -.042 & .017 & -2.48 & .013 \\ \text { Gender (G) } & .225 & .037 & 6.10 & .000 \\ \text { Party Affil. (P) } & .226 & .037 & 6.13 & .000 \\ \text { P x I } & -.200 & .074 & -2.71 & .007 \\ \text { P x E } & -.077 & .034 & -2.29 & .022 \\ \text { Gx I } & -.116 & .074 & -1.58 & .115 \\ \text { Ix E } & .084 & .034 & 2.48 & .013 \\ \text { Px G } & .156 & .074 & 2.11 & .035 \\ \text { Ex G } & -.061 & .034 & -1.80 & .072 \\ \text { Ix Ex G } & .037 & .067 & .56 & .579 \\ \text { Ix Gx P } & -.212 & .148 & -1.43 & .152 \\ \text { Ix Ex P } & .125 & .067 & 1.85 & .065 \\ \text { Ex Gx P } & -.083 & .067 & -1.23 & .219 \\ \text { Ix Gx Ex P } & .135 & .135 & 1.00 & .317 \\ * p=.05, * * p=0.01 \text { level (2-tailed) } & & & \end{array}$




\section{Table S9.}

MTurk/Facebook sample correlations among nine emotions felt toward state employees, collapsed across state employee category.

\begin{tabular}{|c|c|c|c|c|c|c|c|c|c|}
\hline & Pride & Disgust & Admiration & Resentment & Jealousy & Anger & Gratefulness & Fear & Shame \\
\hline Pride & 1 & $-.262 * *$ & $.769 * *$ & $-.195 * *$ & $.087 * *$ & $-.223 * *$ & $.736^{* *}$ & $-.043 *$ & $-.186 * *$ \\
\hline Disgust & & 1 & $-.326 * *$ & $.733^{* *}$ & $.377 * *$ & $.791 * *$ & $-.340 * *$ & $.614 * *$ & $.725^{* *}$ \\
\hline Admiration & & & 1 & $-.240 * *$ & $.067 * *$ & $-.285^{* *}$ & $.779 * *$ & $-.092 * *$ & $-.250 * *$ \\
\hline Resentment & & & & 1 & $.522 * *$ & $.766^{* *}$ & $-.265^{* *}$ & $.650^{* *}$ & $.699 * *$ \\
\hline Jealousy & & & & & 1 & $.485^{* *}$ & $.045^{*}$ & $.542 * *$ & $.461 * *$ \\
\hline Anger & & & & & & 1 & $-.292 * *$ & $.674 * *$ & $.744 * *$ \\
\hline Gratefulness & & & & & & & 1 & $-.097 * *$ & $-.246 * *$ \\
\hline Fear & & & & & & & & 1 & $.692 * *$ \\
\hline Shame & & & & & & & & & 1 \\
\hline
\end{tabular}




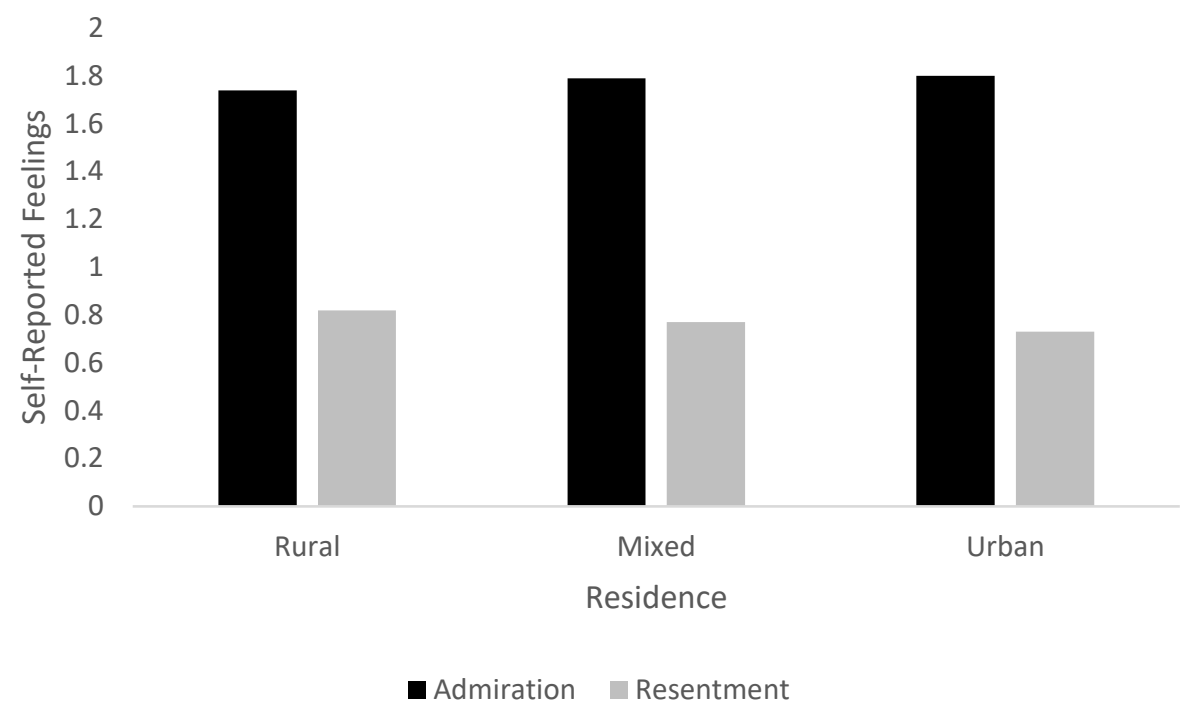

Figure S1. Average ratings of admiration and resentment by rural-urban residence in the UAS sample. 


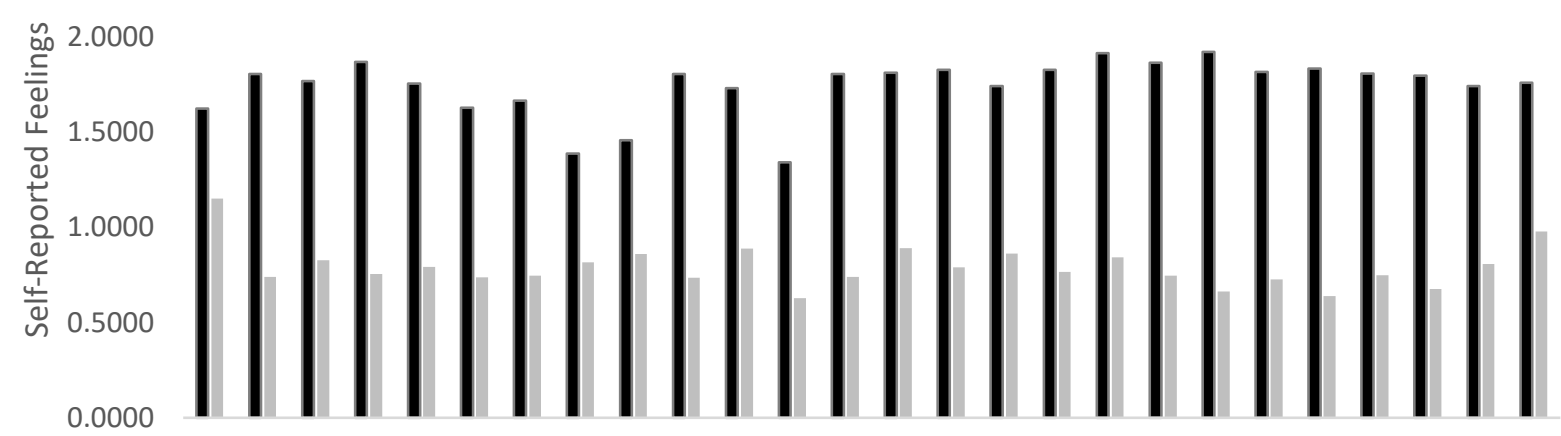
AK AL AR AZ CA CO CT DC DE FL GA HI IA ID IL IN KS KY LA MA MD ME MI MN MO MS State

$$
\text { admiration } \square \text { Resentment }
$$

2.5000

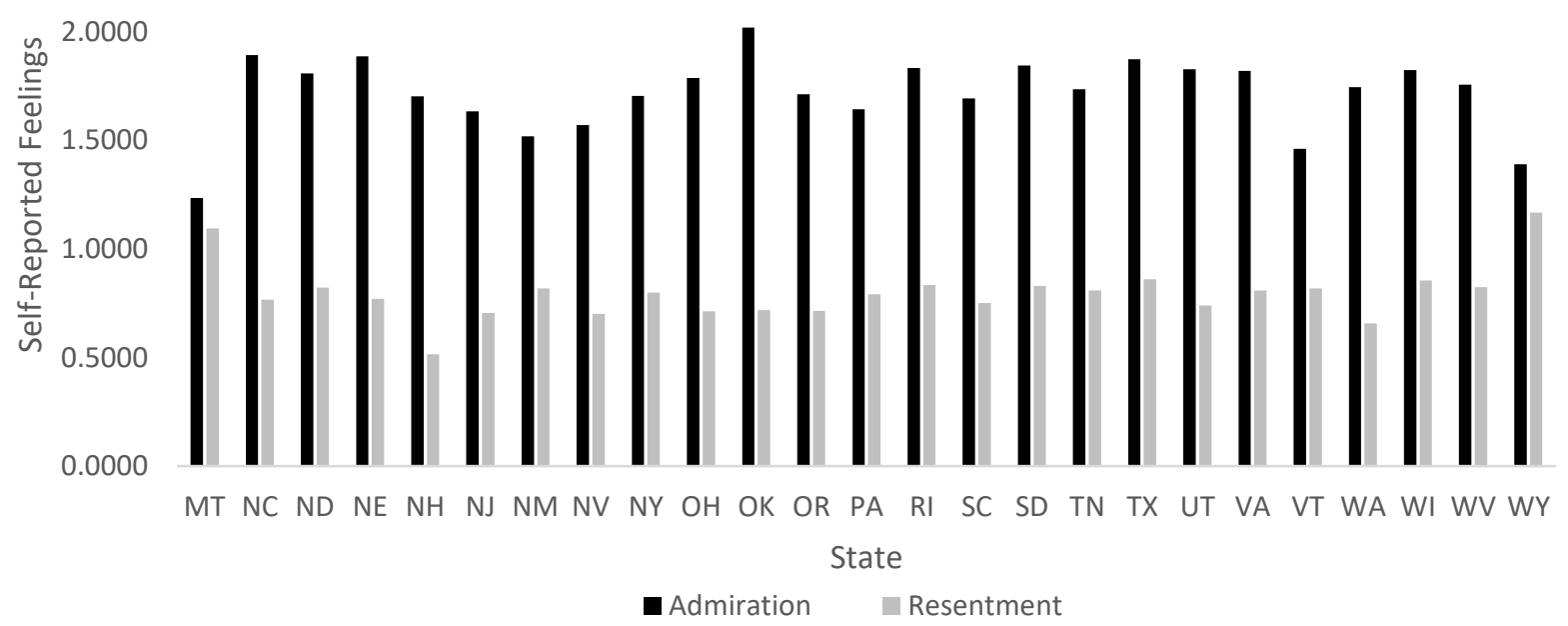

Figure S2. Average rating of admiration and resentment across all 50 US states and Washington D.C. in the UAS sample. 


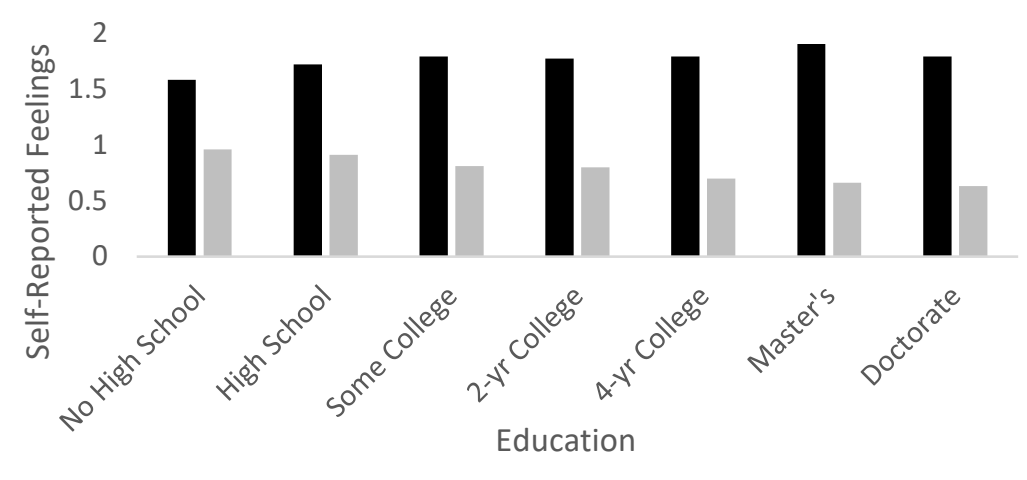

- Admiration Resentment

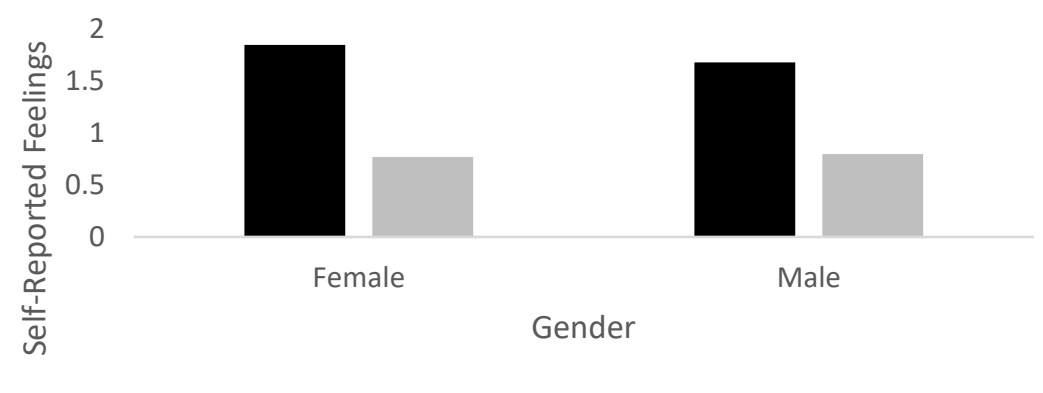

- Admiration Resentment

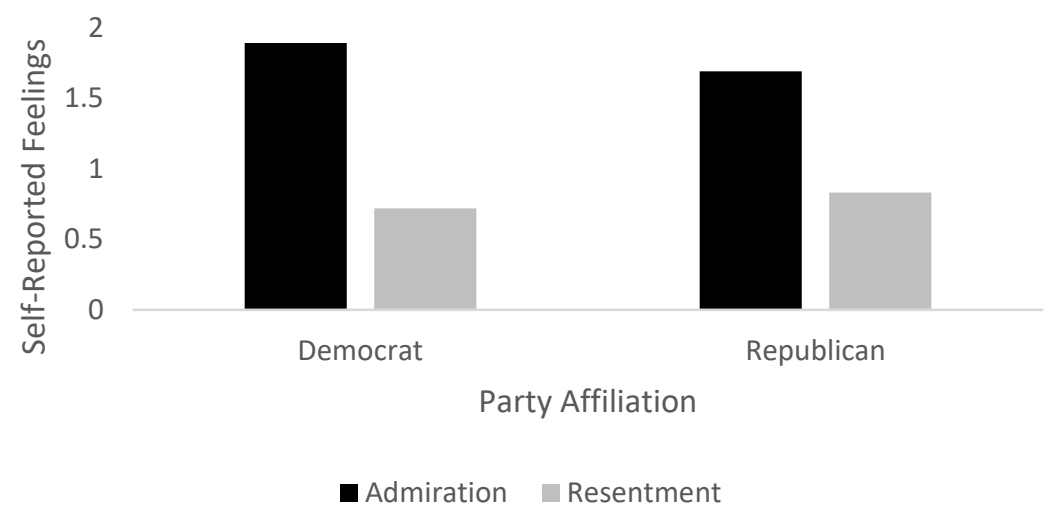

Figure S3. Resentment and admiration by Education, Gender, and Party Affiliation in the UAS sample. 


\section{MTurk/Facebook Sample}
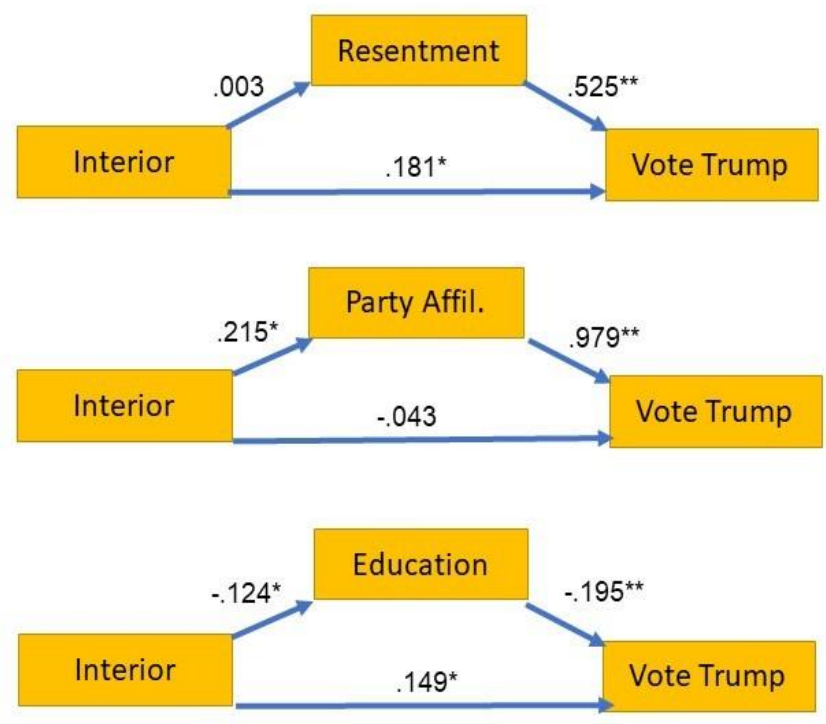

Figure S4.

Resentment, Party Affiliation, and Education in voting. Mediational models using the MTurk/Facebook sample. Coefficients are unstandardized. Findings reveal significant partial mediation by resentment, party affiliation, and education of rural residence on voting. Coding of the variables was as follows: urban/rural classification, $0=$ urban, $1=$ mixed urban/rural, $2=$ rural; state of residence, $0=$ elite coastal state, $1=$ interior state; education, $1=$ lowest, $7=$ highest, treated as a continuous variable; party affiliation, $0=$ Democrat, $1=$ Republican. ${ }^{*} p<.05$, ** $p<$ 0.01 level (2-tailed). See Supplementary Text S2 for details. 


\section{MTurk/Facebook Sample}

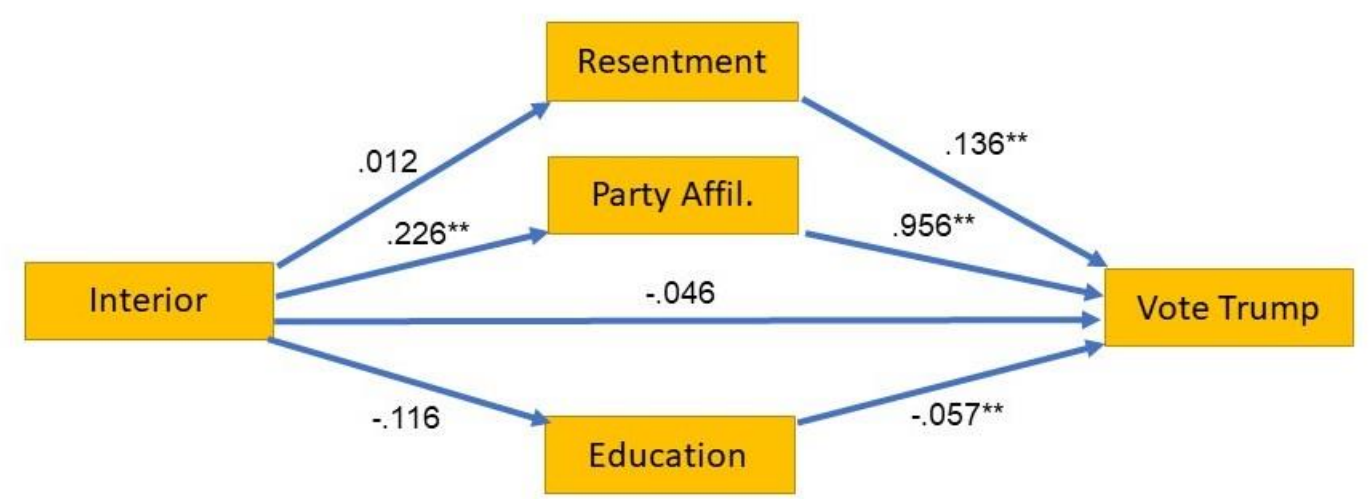

Figure S5.

Resentment, Party Affiliation, and Education as parallel mediators in voting behavior.

Mediational models using the MTurk/Facebook sample. Coefficients are unstandardized.

Findings reveal significant partial mediation by party affiliation and education of rural residence on voting, but not resentment. Coding of the variables was as follows: state of residence, $0=$ elite coastal state, 1 = interior state; education, $1=$ lowest, $6=$ highest, treated as a continuous variable; party affiliation, $0=$ Democrat, $1=$ Republican. ${ }^{*} p<.05, * * p<0.01$ level (2-tailed). See Supplementary Text S2 for details. 